UNIVERSIDADE DE SÃO PAULO

FACULDADE DE MEDICINA DE RIBEIRÃO PRETO

PROGRAMA DE PÓS-GRADUAÇÃO EM CLÍNICA MÉDICA

DESENVOLVIMENTO DE UM INSTRUMENTO DE TRIAGEM NUTRICIONAL,

PARA PACIENTES COM CÂNCER EM SEGUIMENTO AMBULATORIAL

ALUNO: THAUANY NANTES GUIRÁO

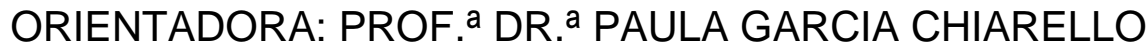

RIBEIRÃO PRETO

2021 


\section{UNIVERSIDADE DE SÃO PAULO \\ FACULDADE DE MEDICINA DE RIBEIRÃO PRETO \\ PROGRAMA DE PÓS-GRADUAÇÃO EM CLÍNICA MÉDICA}

DESENVOLVIMENTO DE UM INSTRUMENTO DE TRIAGEM NUTRICIONAL, PARA PACIENTES COM CÂNCER EM SEGUIMENTO AMBULATORIAL

Dissertação apresentada ao Programa de PósGraduação em Clínica Médica da Faculdade de Medicina de Ribeirão Preto da Universidade de São Paulo para obtenção do título de Mestre em Investigação Biomédica

Aluna: Thauany Nantes Guiráo

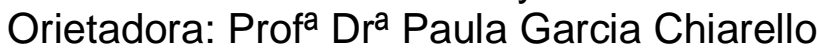


Autorizo a reprodução e divulgação total ou parcial deste trabalho, por qualquer meio convencional ou eletrônico, para fins de estudo e pesquisa, desde que citada a fonte.

Guiráo, Thauany Nantes

Desenvolvimento de um instrumento de triagem nutricional para pacientes com câncer, em seguimento ambulatorial. Ribeirão Preto, 2021.

63 p. : il. ; $30 \mathrm{~cm}$

Dissertação de Mestrado, apresentada à Faculdade de Medicina de Ribeirão Preto/USP. Área de concentração: Investigação Biomédica.

Orientador: Garcia Chiarello, Paula.

1. Câncer. 2. Desnutrição. 3. Triagem nutricional. 4. Ambulatório. 5. Risco nutricional. 


\title{
DESENVOLVIMENTO DE UM INSTRUMENTO DE TRIAGEM NUTRICIONAL, PARA PACIENTES COM CÂNCER EM SEGUIMENTO AMBULATORIAL
}

\author{
Dissertação, apresentado a \\ Universidade de São Paulo, como \\ parte das exigências para a \\ obtenção do título de Mestre em \\ Investigação biomédica.
}

Ribeirão Preto, de de

BANCA EXAMINADORA

Prof. ${ }^{a}$ Drํa Paula Garcia Chiarello

Prof. ${ }^{\mathrm{a}}$

Prof. ${ }^{a}$ 


\section{Dedicatória}

Dedico este trabalho aos meus pais, Ariana e Júnior. Por todo incentivo, confiança e amor que depositam em mim. É um privilégio tê-los como pais.

Ao meu avô Ari, que esta sempre presente em meus pensamentos. Meu avô Manuel, meu maior exemplo. E as minhas avós Marina e Elena, por todo amor, carinho e cuidado.

Nada disto seria possível sem vocês. 


\section{Agradecimentos}

Agradeço a minha orientadora Professora Paula, por toda paciência, empenho e confiança. Ao meu grupo de trabalho que, desde sempre, me ajudaram a realizar esse projeto, Amanda, Bruna, Barbara e Juliana.

Agradeço a minha família, meus tio Sidney e minha tia Ariene, por todo apoio. Meus primos Matheus, Ingryd e Isabella, que me incentivaram a ser melhor.

Agradeço a família que Ribeirão Preto me deu, Fernanda, Sofia, Mariana, Jessica e Raquel, vocês tornam tudo mais fácil. Meu namorado Raphael, por sempre me apoiar e me fazer sentir capaz.

E aos meus amigos, que mesmo longe se fazem sempre presente, Alana, Bianca, Evelyn, Gustavo, Inara e Yumi.

O presente trabalho foi realizado com apoio da Coordenação de Aperfeiçoamento de Pessoal de Nível Superior - Brasil (CAPES) - Código de Financiamento 001. 


\section{Sumário}

LISTA DE FIGURAS E TABELAS:

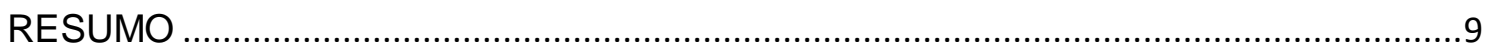

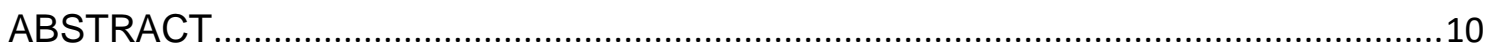

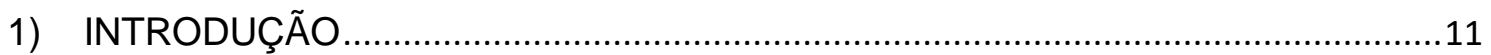

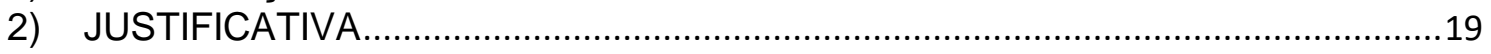

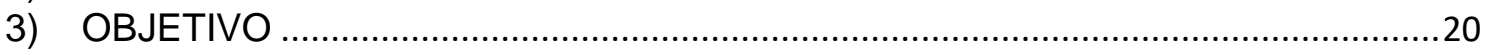

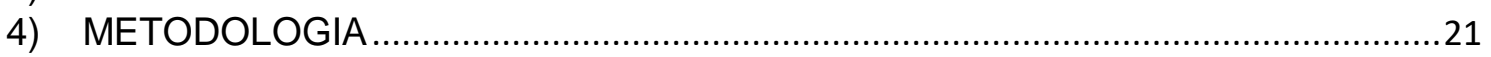

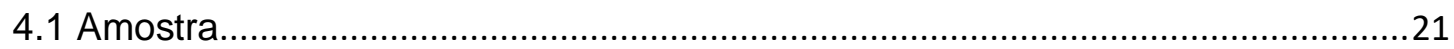

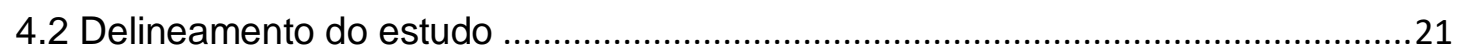

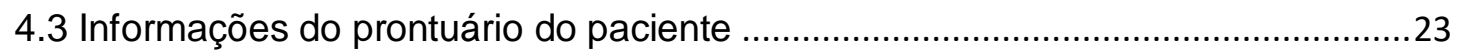

4.4 Composição corporal, antropometria e dinamometria ...........................................23

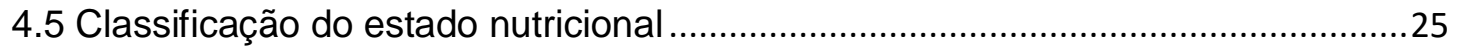

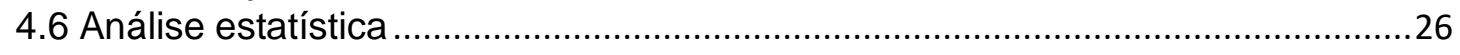

5 - RESULTADOS

6 - DISCUSSÃO

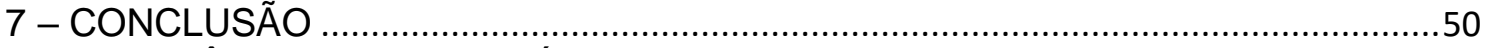

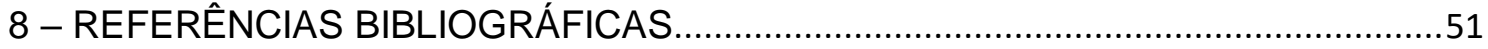

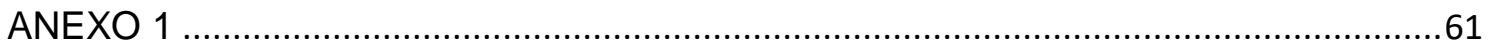

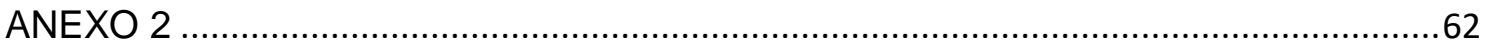

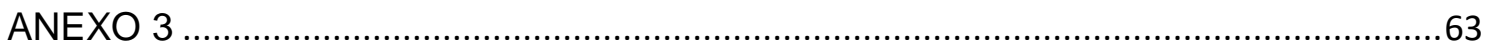




\section{LISTA DE FIGURAS E TABELAS:}

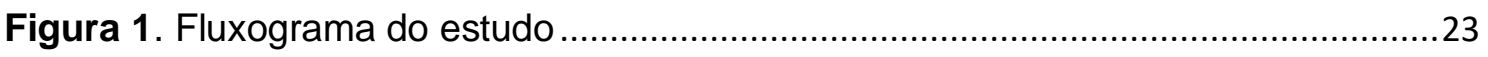

Figura 2. Gráfico de prevalência de sarcopenia.......................................................... 32

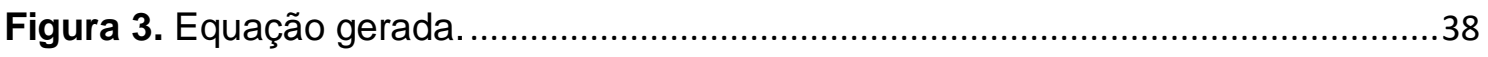

Tabela 1. Prevalência dos tipos de tumores encontrados na amostra..........................28

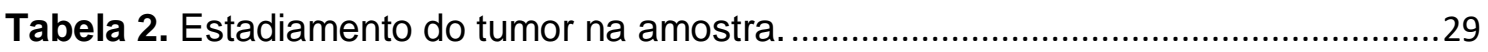

Tabela 3. Tipos de tratamento da amostra, no momento da coleta, em porcentagem (\%).

Tabela 4. Caracterização das vias de alimentação dos pacientes da amostra. .............30

Tabela 5. Pacientes em uso ou não de diuréticos...........................................................

Tabela 6. Caracterização da amostra segundo apetite e ingestão.................................31

Tabela 7. Porcentagem de inadequações para as variáveis estudadas na amostra total......

Tabela 8. Parâmetros antropométricos, em média (+/-DP) para os grupos avaliados. 33

Tabela 9. Parâmetros bioquímicos, em média (+/-DP) para os grupos avaliados. . .33

Tabela 10. Parâmetros de composição corporal, em média (+/-DP) para os grupos avaliados.

Tabela 11. Escala de Karnofsky e ângulo de fase, em média (+/-DP) para os grupos avaliados.

Tabela 12. Correlações significativas entre as variáveis analisadas na amostra...........34

Tabela 13. Força de associação para as variáveis categóricas...................................35

Tabela 14. Impacto das variáveis com força de associação relevantes..........................36

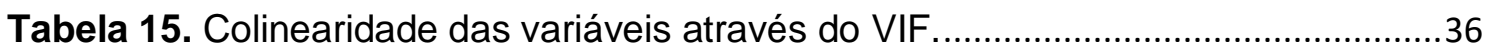

Tabela 16. Análises multivariadas das variáveis selecionadas......................................37

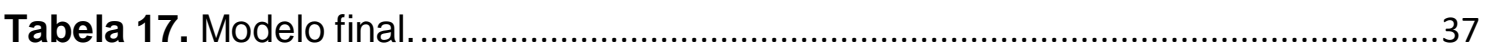




\section{DESENVOLVIMENTO DE UM INSTRUMENTO DE TRIAGEM NUTRICIONAL, PARA PACIENTES COM CÂNCER EM SEGUIMENTO AMBULATORIAL}

\section{RESUMO}

Introdução: A desnutrição é uma realidade comum em muitos hospitais, principalmente em pacientes com câncer. Para evitar o seu diagnostico tardio existem instrumentos de triagem, que auxiliam o profissional a detectar o risco nutricional precocemente, evitando maiores prejuízos para o estado nutricional. Objetivo: Desenvolver uma ferramenta de triagem nutricional para pacientes com câncer, em seguimento ambulatorial. Metodologia: Estudo observacional transversal, realizado em pacientes com câncer, assistidos no Ambulatório de Nutrição Oncológica do HCRP- FMRP - USP. Foram coletados dados de prontuários do atendimento nutricional, como: dados bioelétricos e de composição corporal (por bioimpedância elétrica por espectroscopia), de antropometria (pregas, circunferências e índice de massa corporal), exames bioquímicos de rotina clínica e dinamometria. Os pacientes desnutridos foram identificados por meio de triagem pelo NRS-2002 e classificação pelo critério GLIM, em grupos controle (sem risco e sem desnutrição) e desnutridos. A correlação entre as variáveis no grupo desnutrido foi avaliada pelo método Odds ratio, e para a análise das variáveis que estão mais associadas com a desnutrição foi realizado teste qui-quadrado. Para quantificar a força de associação foi usada a estratégia de modelagem "Stepwise backward". As variáveis que apresentaram melhor sensibilidade e melhor associação ao grupo desnutridos foram incluídas no modelo final. Resultados: A amostra foi composta por 72 pacientes, sendo $58 \%$ do sexo masculino, média de idade de 63 anos $( \pm 13,3)$. O tipo de tumor mais encontrado na amostra foi do trato gastrointestinal. O grupo de desnutridos apresentou maior aparecimento de sarcopenia, pior KPS e menores valores de peso, prega do musculo adutor do polegar (EMAP), índice de massa corporal (IMC), circunferência da panturrilha (CP), dinamometria (HAND), índice de massa gorda (IMG) do que o grupo controle. Nas primeiras analises as variáveis que mais tiveram impacto na desnutrição foram: $C P$, Hidratação, IMC, IMG, MG (em $\mathrm{kg}$ e em \%), ACT, Resistencia, Reatância, KPS, Peso e AEC. Após analises multivariadas e teste de covariância o modelo final foi composto, em forma de equação, por duas variáveis, que mais se associaram à desnutrição, o IMC e o KPS. Conclusão: $O$ instrumento de triagem nutricional desenvolvido neste estudo resultou em uma equação para triagem de risco nutricional, contendo as variáveis KPS e IMC.

Palavras-chave: câncer, desnutrição, risco nutricional, ambulatório, triagem nutricional. 


\title{
DEVELOPMENT OF A NUTRITIONAL SCREENING INSTRUMENT FOR CANCER OUTPATIENTS.
}

\begin{abstract}
Introduction: Malnutrition is a common reality in several hospitals, mainly in patients with cancer. To avoid its late diagnostic there are screening instruments, which help professionals to detect the nutritional risk and avoid its aggravation. Objective: Development of a nutritional screening instrument for patients with cancer in outpatient follow-up. Methodology: Cross-sectional observational study, conducted in cancer patients assisted at the Oncology Nutrition Outpatient Clinic of HCRP - FMRP - USP. Data were collected from medical records of nutritional care, such as: bioelectric and body composition data (by electrical bioimpedance by spectroscopy), anthropometry (pleats, circumferences, and body mass index), routine biochemical tests and dynamometry. Malnourished patients were identified by means of screening by NRS-2002 and GLIM criterion, so patients were divided into control (without risk and without malnutrition) and malnourished. The correlation between the variables in the malnourished group was evaluated by the Odds ratio method, and for the analysis of the variables that are associated with malnutrition, a chisquare test was performed. To quantify the strength of association, the "Stepwise backward" modeling strategy was used. The variables that presented better sensitivity and better association to the malnourished group were included in the final model. Results: The sample consisted of 72 patients, $58 \%$ male, mean age of 63 years $( \pm 13.3)$. The type of tumor most found in the sample was the gastrointestinal tract one. The group of malnourished patients presented higher onset of sarcopenia, worse KPS and lower values of: weight, thumb adductor muscle thickness (TAMT), body mass index (BMI), calf circumference (CC), hand grip, fat mass index (FMI) and fat mass (FM) than the control group. In the first analyses, the variables that had the most impact on malnutrition were: CP, IMC, IMG, MG (kg and \%), total body water (TBW), extra cellular water (ECW), resistance, reactance, KPS, weight and hydration. After multivariate analysis and covariance test, the final model was composed, in the form of an equation, by two variables, which were most associated with malnutrition, BMI and KPS. Conclusion: The nutritional screening instrument developed in this study resulted in an equation for nutritional risk screening, containing the variables KPS and BMI.
\end{abstract}

Keywords: cancer, malnutrition, nutritional risk, ambulatory, nutritional screening. 


\section{1) INTRODUÇÃO}

Uma realidade comum entre a maioria dos hospitais brasileiros é a alta prevalência de desnutrição em pacientes hospitalizados ou em seguimento ambulatorial. ${ }^{1}$ A European Society of Clinical Nutrition and Metabolism (ESPEN) define a desnutrição como "um estado resultante da falta de ingestão ou absorção alimentar, que leva à alteração da composição corporal (diminuição da massa livre de gordura) e massa celular corporal, gerando diminuição de função física e mental'". Esta condição repercute sobre o tratamento de doenças e principalmente sobre a qualidade de vida do paciente, impactando em um pior prognostico e também em maior tempo de internação ou de seguimento ambulatorial, consequentemente com maior custo hospitalar. $^{3}$

A desnutrição não se restringe a um órgão especifico. Pode acometer o pulmão, resultando em pneumonia, devido à redução da massa muscular do diafragma. No fígado pode alterar sua morfologia e provocar atrofia dos hepatócitos e comprometimento das funções hepáticas, como a diminuição da capacidade de metabolizar fármacos e na síntese de albumina e peptídeos. Quando relacionada às funções gastrointestinais, a desnutrição pode levar a quadros que dificultam ainda mais seu tratamento, como a atrofia da mucosa intestinal, diminuição da síntese de enzimas intestinais, aumento da presença de bactérias maléficas à microbiota intestinal, decréscimo das microvilosidades e ainda à síndrome de má absorção. ${ }^{4}$

Algumas doenças tornam mais grave a piora do estado nutricional dos pacientes, como é o caso do câncer. ${ }^{5} \mathrm{O}$ câncer é uma doença altamente catabólica, que tem como principal característica o crescimento desordenado das células, que podem se desenvolver para células agressivas e incontroláveis, levando à formação de tumores que podem acometer tecidos e órgãos. ${ }^{6}$ Atualmente dados mostram que o câncer é a segunda causa de morte no mundo e, segundo estimativas, pode acarretar mais de 21,4 milhões de casos novos nos próximos 30 anos. $^{7}$ 
O Brasil, por ser um pais em desenvolvimento, apresenta um aumento da população idosa, em geral mais suscetível a ocorrência de câncer, que hoje é um dos mais importantes problemas de saúde publica no mundo. Segundo o Instituto Nacional de Câncer José Alencar Gomes da Silva (INCA) para os anos de 2020 a 2022 estima-se que no Brasil ocorrerão 625 mil novos casos de câncer. ${ }^{8}$

Pacientes com câncer possuem maiores riscos de desenvolverem desnutrição, não só pelo aumento da atividade inflamatória, ${ }^{2}$ quanto pelos sintomas causados pela doença e seus tratamentos. ${ }^{9}$ Alguns fatores estão relacionados à desnutrição e o câncer, como o aumento do catabolismo e inflamação causados pela doença, além dos efeitos do tratamento que podem incluir sintomas como anorexia, má absorção alimentar, vômitos, náuseas, entre outros. ${ }^{10} \mathrm{O}$ local do tumor também pode contribuir para o estado de desnutrição, principalmente tumores gástricos ou de cabeça e pescoço, pois interferem diretamente na ingestão alimentar ou absorção de nutrientes. ${ }^{11} \mathrm{~A}$ desnutrição em pacientes com câncer esta associada ao aumento da mortalidade e os pacientes desnutridos podem diminuir sua expectativa de vida em até um ano. ${ }^{12}$

A piora do estado nutricional pode levar a condições que são frequentemente encontradas nestes pacientes, como a caquexia, conhecida como uma síndrome multifatorial caracterizada pela perda de peso involuntária, perda de massa muscular e estado inflamatório. ${ }^{13}$ A caquexia pode ser causada pelos complexos efeitos colaterais referentes a toxicidade do tratamento oncológico, das alterações metabólicas causadas pela doença e alterações na ingestão alimentar. ${ }^{14}$

Outra situação comum encontrada em pacientes com câncer, geralmente simultânea com a desnutrição, é a sarcopenia, condição caracterizada pela perda de massa muscular e de funcionalidade ${ }^{15}$ e que também esta associada à piora na tolerância à quimioterapia pelo aumento da toxicidade, piora no prognostico do paciente e aumento do risco de mortalidade. ${ }^{16,17,18}$ 
Portanto, pacientes com câncer, em sua grande maioria, necessitam manter um acompanhamento nutricional ambulatorial devido às graves consequências que 0 tratamento oncológico pode acarretar no estado nutricional. O objetivo deste acompanhamento é minimizar as condições desfavoráveis ao estado nutricional, trazendo melhor qualidade de vida e aumentar as chances de sobrevida e de recuperação. Porem é usual que estes pacientes, ao serem diagnosticados, já apresentem algum prejuízo no estado nutricional. No Brasil o Sistema Único de Saúde (SUS) tem um prazo de até 60 dias, entre o diagnóstico e o início do tratamento ${ }^{19}$, para atender os pacientes com câncer, justamente porque a demora neste período traz prejuízos ao prognóstico da doença, principalmente em pacientes com maior vulnerabilidade. ${ }^{20}$ Além de já apresentarem piora no estado nutricional estes pacientes podem evoluir com complicações decorrentes da desnutrição, o que dificulta ainda mais seu tratamento. ${ }^{21}$

Visto os males causados pela desnutrição e seu impacto sobre o tratamento do paciente, surgiu à necessidade de estabelecer critérios diagnósticos para a desnutrição, a fim de evitar erros que levem a uma subestimativa dessa condição. Em 2012 a American Society for Parenteral and Enteral Nutrition (ASPEN) publicou critérios para diagnosticar a desnutrição, que levavam em consideração a baixa ingestão alimentar, perda de peso, merda de passa muscular e gordura, acúmulo de fluídos e perda de funcionalidade. ${ }^{22}$ Posteriormente em 2015 a ESPEN também publicou um consenso para diagnostico de desnutrição, porém levando em consideração critérios como Índice de Massa Corporal (IMC) e perda de peso não intencional. ${ }^{23}$ Outra opção muito utilizada é a Avaliação Subjetiva Global (ASG), método clínico de avaliação do estado nutricional que utiliza perda de peso, diminuição da funcionalidade, estresse metabólico, ingestão alimentar e medidas de massa muscular e gordura. ${ }^{24}$

Entretanto, ainda havia a necessidade de um consenso global para o diagnostico de desnutrição. Em 2016, o grupo Global Leadership Initiative on Malnutrition (GLIM), composto pelas principais entidades responsáveis pelo 
assunto, como a ASPEN, ESPEN, a Parenteral and Enteral Nutrition Society of Asia (PENSA) e a Federação Latino-americana de Nutrição Parenteral e Enteral (FELANPE), foi convocado a fim de desenvolver critérios diagnósticos para auxiliar os profissionais da saúde na deteç̧ão da desnutrição. Seu foco é uma abordagem global para a padronização do diagnostico de desnutrição e este consenso ficou conhecido como critério GLIM. ${ }^{25}$ Embora não seja validado no Brasil, países como a Austrália demonstram bons resultados em seus estudos de validação. ${ }^{26}$

Segundo o critério GLIM o primeiro passo para avaliação do estado nutricional do paciente é a triagem de risco nutricional, por meio dos instrumentos de triagem nutricional já validados. Em seguida, aos pacientes que apresentarem risco nutricional aplica-se os critérios GLIM: primeiro analisase 0 bloco etiológico, formado por critérios como absorção e ingestão alimentar, presença de inflamação e classificação das doenças em agudas ou crônicas. Em seguida é feita avaliação fenotípica, onde são avaliadas seis características principais: perda de peso, ingestão insuficiente de energia, exame físico (perda de massa magra, perda de tecido adiposo e presença de edema) e parâmetros de funcionalidade. Dependendo das características apresentadas pelo paciente, segundo a soma destes critérios, o paciente é classificado em desnutrido moderado ou grave, conforme parâmetros estabelecidos.

Um dos principais pontos levantados pelas entidades compositoras do critério GLIM foi a importância de evitar o diagnóstico tardio da desnutrição, contexto em que se destacam os instrumentos de triagem nutricional. ${ }^{25}$ Principalmente em pacientes com câncer, que apresentam um hipercatabolismo maior devido à patologia e ao seu tratamento, é muito importante que esta triagem seja feita o quanto antes. ${ }^{27}$

Os métodos de triagem nutricional têm como objetivo reconhecer precocemente condições nutricionais deficitárias que não foram detectadas antes sobre o estado nutricional destes pacientes, visando uma intervenção dietoterápica que possa prevenir a piora do estado nutricional e auxiliar na 
recuperação. ${ }^{28}$ Após a triagem, pacientes com risco nutricional grave devem receber avaliação mais completa e iniciar a terapia nutricional mais adequada ao seu caso. ${ }^{29}$

A British Association for Parenteral and Enteral Nutrition (BADEN) ressalta que um instrumento de triagem de risco nutricional não fornece diagnóstico de desnutrição, o seu objetivo é demonstrar qual o risco de agravo do estado nutricional daquele paciente. ${ }^{30}$ Existem instrumentos de triagem que podem seguir um modelo de perguntas e repostas, com somatória de pontos ao final, ou em forma de equações matemáticas, em que o resultado é comparado a pontos de corte, que classificam se o paciente esta em risco ou não.

Os instrumentos de triagem devem fundamentar-se em abordagens e procedimentos não invasivos, de fácil compreensão, rápidos e objetivos, principalmente quando se trata de pacientes atendidos em ambulatórios, onde o tempo de atendimento é mais limitado, quando comparado às internações. Visto que nos atendimentos ambulatoriais o volume de pacientes a serem atendidos diariamente é grande, faz-se necessário que o profissional tenha uma abordagem mais objetiva; dessa forma, a realização de uma triagem rápida e direta facilita e otimiza o tempo da consulta. Diante disso, a ESPEN ressalta que o resultado gerado por estas ferramentas deve possuir uma simples interpretação e fornecer de forma prática e correta as condições de risco sobre o estado nutricional dos indivíduos avaliados. ${ }^{31}$

Destacam-se hoje alguns instrumentos de triagem mais utilizados como o Mini Nutritional Assessment (MNA) - Mini avaliação Nutricional (MAN), que avalia não só a história clínica, mas também dados antropométricos e de ingestão alimentar. ${ }^{32}$ A ASG que pode ser usada tanto para triagem de risco quanto para diagnóstico nutricional. ${ }^{33}$ O Nutritional Risk Screening (NRS 2002) que se distingue por considerar a idade do paciente e também detalhamentos sobre condições patológicas. ${ }^{34}$ O Malnutrition Screening Tool (MST) Instrumento de Triagem de Desnutrição ${ }^{35}$ e o Malnutrition Universal Screening 
Tool (MUST) - Instrumento de Triagem Universal de Desnutrição, que no próprio resultado já sugere planos de cuidado nutricional. ${ }^{36}$

Embora alguns destes instrumentos possuam alguma variável relacionada à condição clínica envolvida, nenhum destes até então era específico para o câncer, que por ser uma patologia de alta complexidade necessitaria de um maior detalhamento sobre a condição clínica do avaliado. ${ }^{37}$ Para esta finalidade foi criado o instrumento de triagem nutricional NutriScore, para pacientes com câncer; sua formulação foi baseada no MST com a incorporação de informações como a localização do tumor e a forma de tratamento. ${ }^{38}$ Porem este instrumento ainda não foi validado em cenário ambulatorial, pois na maioria dos estudos é utilizado em enfermarias. ${ }^{39}$

A integração de novos parâmetros nos instrumentos de triagem de risco nutricional se faz necessário hoje, como exposto pela ESPEN. ${ }^{2}$ Esta integração deve investigar tanto parâmetros antropométricos, como dados bioquímicos, composição corporal e clínicos. ${ }^{24}$

Outras variáveis clinicas também são importantes na avaliação mais integral do paciente com câncer, como a escala de performance de Karnofsky ( Karnofsky Performance Status - KPS $)^{40}$, que classifica os pacientes de acordo com o grau de funcionalidade, levando em consideração fatores como desempenho físico e a capacidade de realizar atividades do cotidiano. A escala foi criada em 1949 com o objetivo de analisar e acompanhar o desempenho geral do paciente, principalmente em pacientes submetidos à quimioterapia. Ao longo dos anos a escala foi aperfeiçoada e validada em pacientes com câncer e em outras comorbidades..$^{41} \mathrm{O}$ uso do KPS em pacientes com câncer é muito usual na pratica clinica, a fim de não só analisar a funcionalidade, mas também a qualidade de vida e prognóstico destes. ${ }^{42}$

A análise bioquímica também pode contribuir para a avaliação do risco nutricional e exames como albumina sérica, proteínas totais e proteína c reativa (PCR) têm auxiliado o nutricionista a ter uma visão mais ampla sobre o estado de seu paciente, principalmente em pacientes com câncer, onde o estado 
inflamatório é muito presente e por isso tende a alterar estes parâmetros. ${ }^{43}$ Alguns instrumentos de triagem já utilizam estas variáveis, como o Nutritional Risc Index (NRI) que utiliza em sua fórmula valores de albumina sérica e peso corporal para identificar o risco nutricional. ${ }^{44}$

A composição corporal, como já citado, é um critério importante para a avaliação do estado nutricional, na medida em que podem fornece informações mais detalhadas sobre massa muscular e distribuição hídrica, fatores importantes a serem avaliados em pacientes com câncer, devido a acentuada perda muscular e alterações hídricas. Existem métodos hoje considerados padrão outro para avaliação da composição corporal, como, por exemplo, o uso da BIA (Bioelectrical Impedance Analysis) e do DEXA (Dual-Energy X-Ray), porém estes métodos possuem algumas limitações, pois não são todas as instituições que possuem os aparelhos responsáveis pelos exames, além de terem um alto custo de manutenção. ${ }^{45,46}$ Entretanto, existem outros métodos, mais acessíveis, que auxiliam na avaliação da composição corporal e funcionalidade sem necessitarem de aparelhos mais complexos, com o é o caso da circunferência da panturrilha (CP), da espessura do músculo adutor do polegar (EMAP) e do handgrip, que tem demonstrado boas associações a análise de massa muscular e do estado nutricional, também em pacientes com câncer. ${ }^{47,48}$

Por isso, para a criação de um instrumento de triagem é importante a avaliação e integração de variáveis indicadoras de desnutrição e também avaliar as condições clínicas destes pacientes. ${ }^{49}$ Principalmente se tratando de pacientes que possuem doenças inflamatórias, pois estas condições além de causarem alterações na composição corporal, levam a uma diminuição na função biológica do corpo. ${ }^{2}$ Por meio de analises estatísticas é possível a identificação de alguns fatores mais sensíveis para indicar risco e caracterizar quais variáveis serão selecionadas, e até como serão ponderadas, para gerarem resultados comparáveis aos de instrumentos de triagem já validados. 34 
Diante do exposto enfatiza-se a importância da prevenção e de um tratamento eficaz contra a desnutrição, especialmente no curso da doença oncológica. Quanto antes houver o diagnóstico de situações de risco nutricional, mais alta é a chance de prevenção da desnutrição. Instrumentos de triagem devem facilitar este processo, contando com uma aplicação rápida e fácil, de baixo custo e não invasiva, que possam ser direcionadas a situações específicas. 


\section{2) JUSTIFICATIVA}

A justificativa deste estudo baseia-se na busca por instrumentos de triagem de risco nutricional, de rápida e fácil aplicabilidade, que contenham informações disponíveis em atendimento ou em prontuários do paciente e que sejam direcionados a pacientes com câncer, em seguimento ambulatorial. Instrumentos sensíveis na capacidade de triagem destes casos, que mais necessitariam de uma intervenção nutricional precoce, poderiam impactar na melhora do prognóstico e aumento da sobrevida para este grupo. 


\section{3) OBJETIVO}

Desenvolver um instrumento para triagem nutricional de pacientes com câncer, em seguimento ambulatorial.

\subsection{Objetivo Específico}

Caracterizar e comparar os grupos de pacientes com câncer, em acompanhamento ambulatorial, segundo classificação de estado nutricional pelo instrumento GLIM. 


\section{4) METODOLOGIA}

Trata-se de um estudo observacional e transversal, realizado no Ambulatório de Nutrição Oncológica do Hospital das Clínicas de Ribeirão Preto da Universidade de São Paulo (HCRP-USP). A coleta foi realizada de Julho de 2019 a Fevereiro de 2020. Este estudo foi submetido ao Comitê de Ética em Pesquisa do Hospital das Clínicas da Faculdade de Medicina de Ribeirão Preto-USP e aceito sob o número 3.474.024.

Por se tratar de um estudo retrospectivo foi solicitado e aceito pelo Comitê de Ética e Pesquisa a dispensa do Termo de Consentimento Livre e Esclarecido (TCLE), pois as informações utilizadas para elaboração deste estudo são as mesmas geradas em um atendimento nutricional de rotina no referido ambulatório, não expondo o paciente a nenhum procedimento de fora do protocolo de atendimento nutricional. Todavia, reforço o compromisso de manter em sigilo os dados coletados, que serão divulgados apenas em meios acadêmicos e científicos.

\subsection{Amostra}

A amostra de conveniência foi composta por prontuários de pacientes em tratamento nutricional no Ambulatório de Nutrição Oncológica deste HCRPUSP, em consulta de caso novo e retorno, seguindo os critérios de inclusão.

Foram incluídos neste estudo prontuários de pacientes de ambos os sexos, com idade entre 18 e 75 anos que se enquadravam nos seguintes critérios de inclusão:

- Diagnóstico confirmado de neoplasia maligna, seja este de tumor sólido ou hematológicos, sem distinção quanto ao local do tumor;

- Registros de caso novo ou retorno no Ambulatório de Nutrição Oncológica no Hospital das Clínicas da Faculdade de Medicina de Ribeirão Preto - USP; 
Os critérios de exclusão são:

- Casos de pacientes em situações de instabilidade clínica;

- Casos de pacientes que não possuíam todos os dados da avaliação nutricional registrados no prontuário;

\subsection{Delineamento do estudo}

O projeto é um estudo retrospectivo, considerando a coleta de informações registradas em prontuários dos pacientes, de onde foram anotados dados que possam ser variáveis que afetam o estado nutricional e desta forma podem compor 0 instrumento de triagem. Foram selecionadas variáveis antropométricas, de composição corporal, de funcionalidade, bioquímicas e parâmetros clínicos.

Posteriormente estes dados passaram por análise estatística para verificar quais variáveis se mostraram mais sensíveis ao grupo desnutrido, e então foi elaborado o instrumento de triagem.

\footnotetext{
10 fase $\cdot$ Coleta das variáveis por meio de prontuarios 2o fase

- Avaliação e classificaçãodo estado nutricional

- Análise estatistica

3o fase • Seleção das variáveis mais sensiveis ao risco de desnutrição

4음 fase

- Elaboração do instrumento de triagem
} 
Figura 1: Fluxograma do estudo

\subsection{Informações do prontuário do paciente}

Foram coletados dados de atendimento nutricional e médico. Do atendimento médico foram anotados dados como KPS, diagnóstico do paciente, estadiamento do tumor, tipo de tratamento no momento e uso de medicamentos.

O KPS (Anexo 1) é avaliado no atendimento médico através de uma escala de funcionalidade baseada em quanto a doença ou tratamento impacta na capacidade do paciente em realizar atividades do cotidiano. A escala varia de 0 a $100 \%$, onde $100 \%$ o paciente não apresenta nenhum sintoma e realiza todas as sua atividades sem ajuda ou dificuldades, conforme a funcionalidade do paciente cai e este deixa de fazer suas atividades normais, cuidar de si mesmo sozinho, e começa a demandar cuidados específicos, hospitalização, entre outros, a porcentagem da escala diminui.

\subsection{Composição corporal, antropometria e dinamometria}

Do atendimento nutricional foram coletados dados de composição corporal como: ângulo de fase (AF), massa livre de gordura (MLG), massa gorda (MG), índice de massa livre de gordura (IMLG), índice de massa gorda (IMG), água corporal total (ACT), água intracelular (AIC), água extracelular (AEC), nível de hidratação, resistência e reatância; dados antropométricos como espessura do músculo adutor do polegar (EMAP), dinamometria (HAND), circunferência da panturrilha (CP), peso, altura e índice de massa corporal (IMC). E também dados de exames bioquímicos, retirados do prontuário eletrônico, como: albumina, proteínas totais e proteína c reativa (PCR). Para completar a caracterização dos pacientes foram coletados dados referentes a alterações de apetite e ingestão alimentar.

Estes dados estão incluídos no protocolo de atendimento do ambulatório, sendo assim parte da rotina de atendimentos de todos os pacientes assistidos. Abaixo descreveremos como são feitas estas avaliações 
no atendimento nutricional e quais informações geradas por eles foram consideradas no trabalho.

A bioimpedância, para obtenção da composição corporal, é realizada utilizando-se a Bioimpedância por espectroscopia (BIS), por meio do equipamento multifrequencial (Body Composition Monitor - Fresenius Medical Care $\left.{ }^{\circledR}\right)$, com frequências de 5 à $1000 \mathrm{kHz}$. Os pacientes estavam em decúbito dorsal, em repouso 5 minutos antes da medição permitindo um equilíbrio de fluídos corporais e eletrodos foram afixados na mão e pé direitos. São fixados quatro eletrodos no hemicorpo do paciente, um na mão sendo um próximo à articulação do metacarpo e falange e outro na superfície dorsal da articulação do punho, outro vai na superfície dorsal do tornozelo e o último no pé, no arco transverso da superfície superior. ${ }^{50}$ As informações geradas pelo aparelho são: ângulo de fase, resistência, reactância, capacitância, IMC, MG, MLG, IMG, IMLG, ACT, AIC, AEC e hiper hidratação $(\mathrm{HH})$.

Os pontos de corte para a MLG, MG, IMLG E IMG são classificados de acordo com idade e gênero, segundo a literatura. ${ }^{51} \mathrm{O}$ nível de hidratação é classificado de acordo com parâmetros estabelecidos do fabricante do aparelho de bioimpedância. Para a bioimpedância por espectroscopia o método consiste em dividir os compartimentos corporais em 3 partes, massa livre de gordura, massa gorda e hiper hidratação e calcular a água extracelular esperada menos a água extracelular medida. ${ }^{52,53}$

Para a antropometria são utilizadas medidas como peso, altura, IMC, EMAP e CP. O peso é aferido por balança digital e a altura por estadiometro. $O$ IMC é aferido pelo cálculo: peso $(\mathrm{kg})$ dividido pela altura $(\mathrm{m})$ ao quadrado. ${ }^{54}$ Sendo os valores de referencia para adultos eutróficos entre 18,5 a 24,9kg/m², abaixo de $18,5 \mathrm{~kg} / \mathrm{m}^{2}$ pacientes com baixo peso e acima de 24,9 e 29,9 kg/m² sobrepeso e obesidade, respectivamente. ${ }^{55}$ Para idosos foram considerados eutróficos os pacientes que apresentaram IMC entre 23 e $28 \mathrm{~kg} / \mathrm{m}^{2}$, baixo peso a valores menores que $23 \mathrm{~kg} / \mathrm{m}^{2}$ e sobrepeso para valores acima de $28 \mathrm{~kg} / \mathrm{m}^{2}{ }^{56}$ 
A EMAP é aferida através de adipômetro manual da marca Lange $\AA$, com precisão de $1 \mathrm{~mm}$. O exame consta em o paciente sentado com a mão apoiada sobre os joelhos e os dedos abertos, então é pinçado o músculo adutor entre a extensão do polegar e o indicador. Exame realizado na mão dominante, repetido três vezes e o valor final a ser considerado é a média entres estes. ${ }^{57}$ Com pontos de corte de $13,4 \mathrm{~mm}$ para mão dominante e $13,1 \mathrm{~mm}$ para mão não dominante. ${ }^{58}$

Para aferição da CP, o exame consiste no paciente sentado com os pés no chão e pernas inclinadas em 90º, através de uma fita métrica $(\mathrm{cm})$ é aferido a circunferência da maior parte da panturrilha. O ponto de corte considerado foi de $33 \mathrm{~cm}$ para mulheres e $34 \mathrm{~cm}$ para homens. ${ }^{59}$

O teste de funcionalidade é feito através do exame de dinamometria, realizado por meio do dinamômetro modelo MG 4800 digital Charder ${ }^{\circledR}$. O exame consiste no paciente sentado, com braço dobrado em $90^{\circ}$ segurando 0 aparelho, após instruções de como segurá-lo o instrutor, previamente treinado, pede ao paciente para apertá-lo com o máximo de força possível e soltá-lo. ${ }^{60} \mathrm{O}$ resultado é mostrado no visor do aparelho. $O$ exame é repetido três vezes e considera-se o maior resultado. Não existe na literatura até o presente momento valores de referência para pacientes com câncer e nem um consenso para população brasileira, por isso serão considerados pontos de corte segundo idade e gênero, segundo a literatura. ${ }^{61}$

\subsection{Classificação do estado nutricional}

Todas as informações necessárias para a avaliação do estado nutricional estavam no prontuário do paciente. Para esta avaliação foi utilizado primeiramente o instrumento de triagem, o Nutricional Risk Screening 2002 (NRS 2002) ${ }^{34}$. O método conta com 2 partes, sendo a primeira composta pela história clínica do paciente, referente a história de alterações ponderais, alterações na ingestão alimentar e estado de saúde. Já a segunda leva em consideração o estado nutricional e a gravidade da doença. Ao final tem-se um 
score onde os pacientes que apresentaram score final maior ou igual a 3 , foram classificados em risco nutricional. (Anexo 2)

Para os pacientes em risco nutricional, segundo o NRS, foi aplicado o critério GLIM para diagnosticar se havia desnutrição, para o uso deste critério foram considerados fatores etiológicos, como perda de apetite, redução da ingestão alimentar e gravidade da doença com presença ou não de inflamação, e fatores fenótipos como perda de peso, baixo IMC e redução da massa muscular (que neste estudo foi avaliada por meio de bioimpedância por espectroscopia). Em seguida os pacientes que apresentavam a soma de um ou mais fatores etiológicos com um ou mais fatores fenótipos foram classificados com desnutrição moderada ou grave, dependendo da somatória final. ${ }^{25}$ (Anexo 3)

\subsection{Análise estatística}

Foi utilizado o método de regressão logística para avaliar o efeito de cada uma das variáveis no estado nutricional do paciente, observando para cada variável qual seu efeito no risco de desnutrição. ${ }^{49}$

Para comparação entre grupos foi utilizado test t e teste qui-quadrado. Para correlações entre as variáveis foi utilizado o teste de correlação de Pearson, pelo software R.

A desnutrição foi considerada uma variável dependente e as demais variáveis consideradas independentes. A desnutrição foi considerada uma variável binária (que expressa presença ou ausência) e a força da associação entre esta e as demais variáveis foi analisada em valores de razão chances ou Oddsratio (OR).

Para a análise das variáveis que possam estar associadas a desnutrição foi realizado teste qui-quadrado e em seguida, para quantificar a força de associação, análise múltipla pela estratégia de modelagem step wise backward. 
Para as variáveis numéricas inicialmente foi aplicado o teste de normalidade de Kolmogorov-Smirnov para verificar se as variáveis possuem ou não distribuição normal. Nas variáveis em que não foi rejeitada a hipótese de normalidade $(p>0,05)$ em ambos os grupos foi aplicado o teste t de Student para comparação dos grupos. Nas variáveis em que rejeitamos a hipótese de normalidade $(p \leq 0,05)$ foi aplicado o teste não paramétrico de Mann-Whitney na comparação.

Para verificar a interferência de cada variável entre si foi realizado análise multivariada nas variáveis independentes que apresentaram relação significativa com a desnutrição e posteriormente foi calculado a colinearidade entre estas variáveis através do Variance Inflation Factor (VIF).

As variáveis que foram mais significativas e apresentaram melhor sensibilidade e melhor associação ao grupo de pacientes desnutridos formaram o modelo final. 


\section{5 - RESULTADOS}

A amostra foi composta inicialmente por 79 pacientes, porém 5 foram excluídos por não apresentarem os dados completos nos prontuários e 2 por não completarem as avaliações de composição corporal, portanto a amostra final foi composta por 72 pacientes, estes foram divididos em grupos controle e desnutridos, pelos critérios expostos na metodologia, resultando em 32 pacientes no grupo controle e 40 no grupo de risco, dos 40 pacientes em risco todos foram diagnosticados com desnutrição, segundo o GLIM, e compuseram o grupo desnutrido, dentre os desnutridos $52,5 \%$ apresentavam desnutrição grave.

A maioria da amostra foi do sexo masculino (58\%) com média de idade de 63 anos (desvio padrão $\pm 13,3$ ). $O$ tipo de tumor mais encontrado na amostra foi do trato gastrointestinal, correspondendo a $83 \%$ da amostra total (Tabela1). O estadiamento T4 foi o mais encontrado e da amostra total $13 \%$ apresentaram metástase (Tabela 2).

Tabela 1. Prevalência dos tipos de tumores encontrados na amostra.

\begin{tabular}{lccc}
\hline \multicolumn{1}{l}{ Tipos de tumores } & \multicolumn{3}{c}{$\mathrm{n}(\%)$} \\
\hline Trato gastrointestinal & $60(83 \%)$ & Controle & Desnutridos \\
Ovário & $2(2,9 \%)$ & $25(77 \%)$ & $35(87 \%)$ \\
Pulmão & $6(8,6 \%)$ & $2(6,5 \%)$ & 0 \\
Mama & $2(2,9 \%)$ & $2(3,5 \%)$ & $15(13 \%)$ \\
Linfoma & $2(2,9 \%)$ & $2(6,5 \%)$ & 0 \\
\hline
\end{tabular}




\begin{tabular}{|c|c|c|c|}
\hline & Total & Controle & Desnutridos \\
\hline $\begin{array}{l}\text { Estadiamen } \\
\mathbf{T}\end{array}$ & \multicolumn{3}{|c|}{$\mathrm{n}(\%)$} \\
\hline $\mathrm{T} 1$ & $11(18 \%)$ & $4(16 \%)$ & 7 (20\%) \\
\hline T2 & $10(17 \%)$ & $9(36 \%)$ & $1(3 \%)$ \\
\hline T3 & 11 (18\%) & $3(8 \%$ & $8(23 \%)$ \\
\hline T4 & 22 (37\%) & $9(36)$ & $13(39 \%)$ \\
\hline $\begin{array}{l}\text { TX } \\
\mathbf{N}\end{array}$ & $6(10 \%)$ & $1(4 \%)$ & $5(15 \%)$ \\
\hline No & $23(39 \%)$ & $9(36 \%)$ & $14(42 \%)$ \\
\hline N1 & 12 (20\%) & 7 (28\%) & $5(15 \%)$ \\
\hline N2 & $13(22 \%)$ & $5(20 \%)$ & $8(23 \%)$ \\
\hline N3 & $4(6 \%)$ & $2(8 \%)$ & $2(5 \%)$ \\
\hline$N X$ & $8(13 \%)$ & $3(8 \%)$ & $5(15 \%)$ \\
\hline Metástase & $8(13 \%)$ & $2(8 \%)$ & $6(18 \%)$ \\
\hline
\end{tabular}

T: Tumor primário; N: Linfonodos regionais.

A maior parte da amostra não apresentava medidas terapêuticas para o tratamento oncológico no momento, dentre os que estavam em tratamento a maioria estava realizando quimioterapia, a maior parte em quimioterapia estava no grupo de desnutridos (Tabela 3).

Tabela 3. Tipos de tratamento da amostra, no momento da coleta, em porcentagem (\%).

\begin{tabular}{cccc}
\hline & Total & Controle & Desnutridos \\
\hline & $\mathrm{n}(\%)$ & $\mathrm{n}(\%)$ & $\mathrm{n}(\%)$ \\
$\begin{array}{c}\text { Quimioterapia } \\
\text { Radioterapia }\end{array}$ & $\begin{array}{c}12(17 \%) \\
6(8 \%)\end{array}$ & $3(9 \%)$ & $9(23 \%)$ \\
$\begin{array}{c}\text { Quimioterapia e } \\
\text { radioterapia } \\
\text { Cuidados } \\
\text { paliativos }\end{array}$ & $6(8 \%)$ & $4(13 \%)$ & $2(5 \%)$ \\
$\begin{array}{c}\text { Sem medidas } \\
\text { terapêuticas no } \\
\text { momento }\end{array}$ & $44(61 \%)$ & $23(72 \%)$ & $21(52 \%)$ \\
\hline
\end{tabular}


Dentre a amostra 7\% apresentava via alternativa de alimentação, como a nutrição enteral (Tabela 4), nenhum paciente da amostra estava utilizando a via parenteral, e $28 \%$ estava em uso de diuréticos (Tabela 5).

\begin{tabular}{|c|c|c|c|}
\hline & Total & Controle & Desnutridos \\
\hline & n (\%) & n (\%) & $\mathrm{n}(\%)$ \\
\hline Via oral & $67(93 \%)$ & 30 (94\%) & 37 (92\%) \\
\hline Via enteral & $5(7 \%)$ & $2(6 \%)$ & $3(8 \%)$ \\
\hline
\end{tabular}

\begin{tabular}{|c|c|c|c|}
\hline & Total & Controle & Desnutridos \\
\hline & n (\%) & n (\%) & $\mathrm{n}(\%)$ \\
\hline $\begin{array}{l}\text { Uso de } \\
\text { diuréticos }\end{array}$ & $20(28 \%)$ & 11 (34\%) & 9 (25\%) \\
\hline $\begin{array}{c}\text { Sem uso } \\
\text { de } \\
\text { diuréticos }\end{array}$ & 52 (72\%) & 21 (66\%) & 31 (75\%) \\
\hline
\end{tabular}

A maioria da amostra apresentou apetite e ingestão alimentar preservados (Tabela 6), porem os que mais apresentaram apetite e ingestão alimentar diminuídos estavam no grupo de desnutridos. Dos pacientes que estavam em tratamento, quimioterapia e/ou radioterapia, 50\% apresentavam apetite diminuído e $41 \%$ ingestão diminuída. Dos que não estavam realizando nenhum tratamento, $66 \%$ estavam com apetite preservado e $61 \%$ com ingestão preservada. 
Tabela 6. Caracterização da amostra segundo apetite e ingestão.

\begin{tabular}{cccc}
\hline & Total & Controle & Desnutridos \\
\hline Ingestão & $\mathrm{n}(\%)$ & $\mathrm{n}(\%)$ & $\mathrm{n}(\%)$ \\
Preservada & $39(54 \%)$ & $19(56 \%)$ & $20(50 \%)$ \\
Diminuída & $24(34 \%)$ & $8(25 \%)$ & $16(40 \%)$ \\
Aumentada & $9(12 \%)$ & $5(16 \%)$ & $4(10 \%)$ \\
& & & \\
Apetite & & & \\
Preservado & $40(55 \%)$ & $20(62 \%)$ & $20(50 \%)$ \\
Diminuído & $22(31 \%)$ & $6(19 \%)$ & $16(40 \%)$ \\
Aumentado & $10(14 \%)$ & $6(19 \%)$ & $4(10 \%)$ \\
\hline
\end{tabular}

Para algumas variáveis houve uma porcentagem significativa de inadequação na amostra total, principalmente em parâmetros de funcionalidade, como a dinamometria, como visto na Tabela 7. Para o IMC $59,7 \%$ da amostra estavam com valores abaixo da faixa de normalidade e $12,5 \%$ acima da faixa de normalidade. O IMG apresentou-se alto para $48,5 \%$ da amostra e baixo para $10,3 \%$, as demais variáveis apresentam-se inadequadas quando abaixo dos valores de referencia, com exceção da PCR que esta inadequada quando aumentada. Dentre a amostra $61 \%$ apresentava sarcopenia, segundo os parâmetros europeus para diagnostico, e no grupo desnutridos $99 \%$ apresentavam sarcopenia. ${ }^{2}$ A sarcopenia foi maior no grupo desnutrido do que no controle (Figura 2). 
Tabela 7. Porcentagem de inadequações para as variáveis estudadas na amostra total.

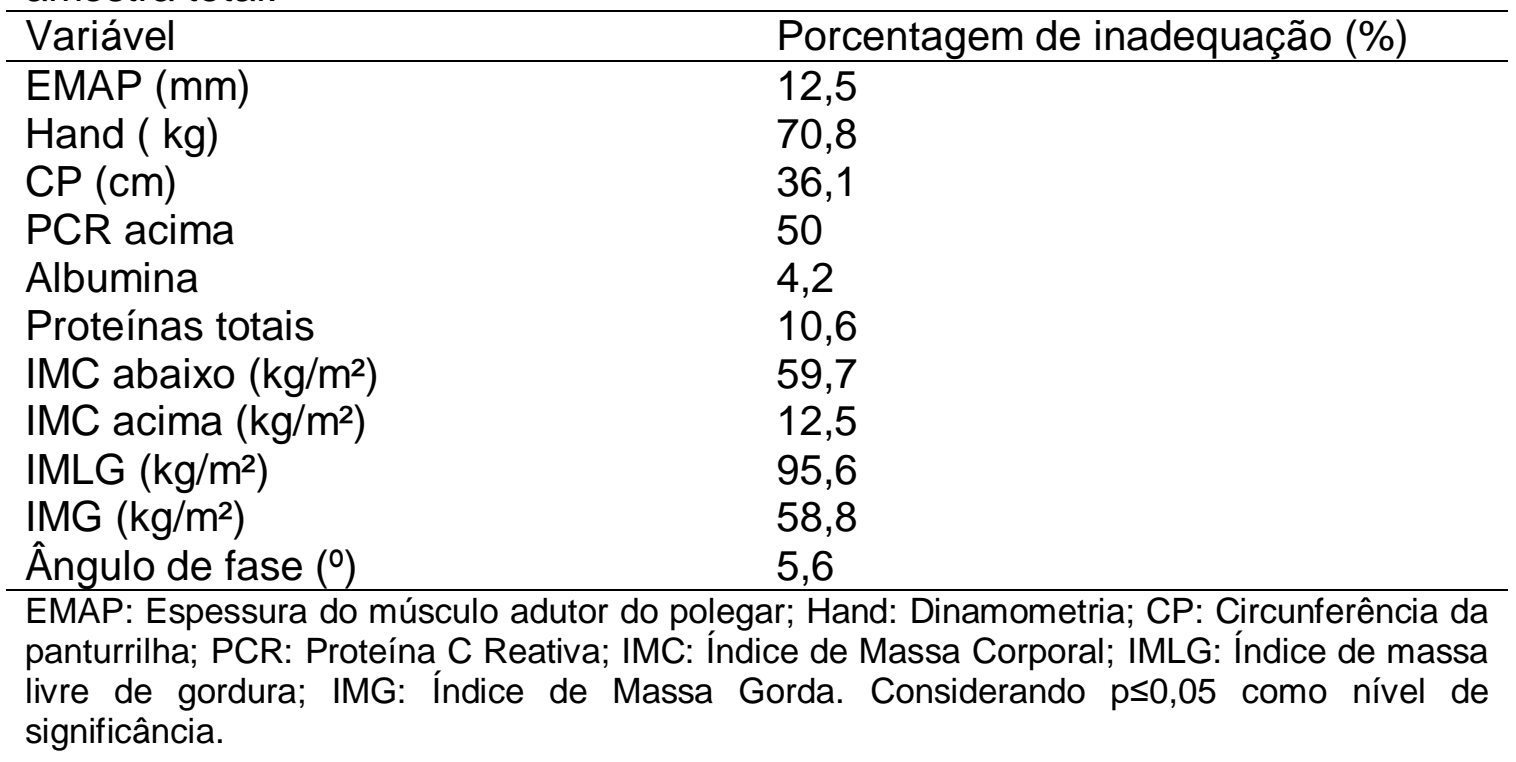

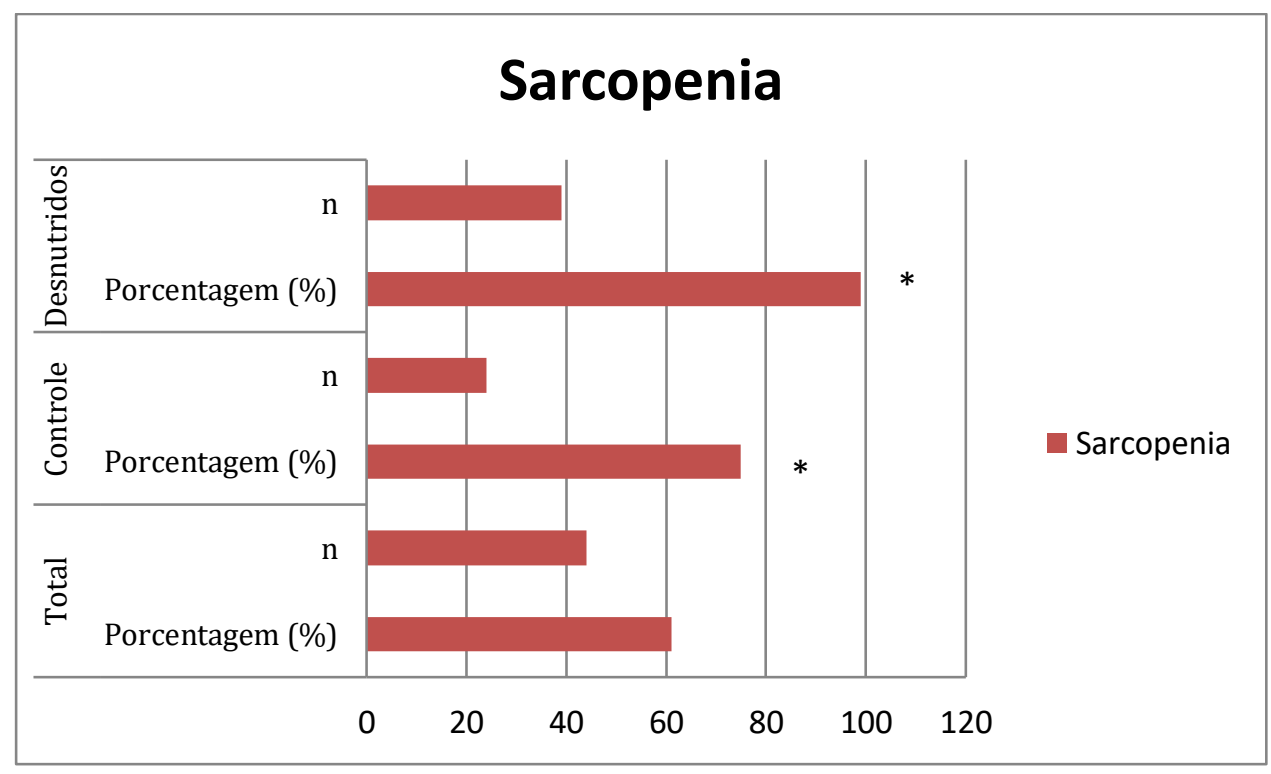

Figura 2. Gráfico de prevalência de sarcopenia. $\quad{ }^{*} p<0,005$.

A Tabela 8 mostra diferenças das variáveis de antropometria e funcionalidade entre os grupos. Todas as variáveis antropométricas e de funcionalidade foram menores no grupo desnutrido. Diferente dos parâmetros bioquímicos, em que apenas a PCR apresentou-se menor nos desnutridos, as demais permaneceram semelhantes entre os grupos (Tabela 9). 
Tabela 8. Parâmetros antropométricos, em média (+/-DP) para os grupos avaliados.

\begin{tabular}{ccc}
\hline & Controle $(\mathrm{n}=32)$ & Desnutrido $(\mathrm{n}=40)$ \\
\hline & Media & Media \\
Hand & $26,8 \pm 10$ & $23,8 \pm 7,6$ \\
$(\mathrm{~kg})^{*}$ & & \\
EMAP & $16,5 \pm 5,4$ & $15 \pm 3,9$ \\
$(\mathrm{~mm})^{*}$ & & \\
$\mathrm{CP}(\mathrm{cm})^{*}$ & $34,6 \pm 4,8$ & $30,7 \pm 3,7$ \\
Peso $(\mathrm{kg})^{*}$ & $66 \pm \pm 19,5$ & $50,6 \pm 10,3$ \\
$\mathrm{IMC}$ & $23,8 \pm 6,9$ & $18,8 \pm 3,0$ \\
$\left(\mathrm{~kg} / \mathrm{m}^{2}\right)^{*}$ & & \\
\hline Hand: Dinamometria; EMAP: Espessura do músculo adutor do polegar; CP: Circunferência da \\
panturrilha; IMC: İndice de Massa Corporal; N: número amostral; DP: Desvio Padrão. ${ }^{*} \mathrm{p}<0,005$.
\end{tabular}

Tabela 9. Parâmetros bioquímicos, em média (+/-DP) para os grupos avaliados.

\begin{tabular}{ccc}
\hline & Controle & Desnutrido \\
PCR $^{*}$ & $0,6 \pm 1,8$ & $0,55 \pm 2,7$ \\
Albumina & $4,1 \pm 0,4$ & $4,1 \pm 0,3$ \\
Proteínas totais & $6,9 \pm 0,6$ & $6,8 \pm 0,7$ \\
\hline
\end{tabular}

PCR: Proteína C Reativa; DP: Desvio padrão. ${ }^{\star} \mathrm{p}<0,005$.

Já segundo os parâmetros de composição corporal o IMG e a MG foram os que mais apresentaram diferenças entre os grupos, apresentaram-se maiores no grupo controle (Tabela 10), os parâmetros clínicos também não demonstraram diferenças, apesar do KPS estar menor no grupo desnutrido (Tabela 11). 
Tabela 10. Parâmetros de composição corporal, em média (+/-DP) para os grupos avaliados.

\begin{tabular}{ccc} 
& Controle & Desnutridos \\
\hline $\mathrm{IMLG}\left(\mathrm{kg} / \mathrm{m}^{2}\right)$ & $12,3 \pm 2,6$ & $12,4 \pm 1,8$ \\
$\mathrm{IMG}\left(\mathrm{kg} / \mathrm{m}^{2}\right)^{*}$ & $11,5 \pm 7,5$ & $6,3 \pm 2,8$ \\
$\mathrm{MLG}(\mathrm{kg})$ & $34,4 \pm 9,8$ & $32,1 \pm 6,6$ \\
$\mathrm{MG}(\mathrm{kg})^{*}$ & $22,1 \pm 13,7$ & $11,8 \pm 5,6$ \\
$\operatorname{Res}(\mathrm{Ohm})$ & $617,3 \pm 122,4$ & $709,1 \pm 115,3$ \\
Reac(Ohm) & $1604,5 \pm 507,3$ & $1899,9 \pm 493,9$ \\
$\mathrm{E} / \mathrm{l}(\mathrm{L})$ & $0,89 \pm 4,3$ & $0,86 \pm 0,12$ \\
$\mathrm{AEC}(\mathrm{L})$ & $15,9 \pm 3,4$ & $12 \pm 2,7$ \\
$\mathrm{AIC}(\mathrm{L})$ & $17,9 \pm 4,3$ & $14,9 \pm 3,0$ \\
$\mathrm{ACT}(\mathrm{L})$ & $34,0 \pm 7,4$ & $26,5 \pm 5,3$ \\
$\mathrm{HD}(\mathrm{L})$ & $0,9 \pm 1,7$ & $0,75 \pm 1,6$ \\
\hline
\end{tabular}

IMLG: İndice de massa livre de gordura; IMG: Índice de Massa Gorda; MLG: Massa Magra; MG: Massa Gorda; Res: Resistência; Reac: Reatância;E/l: Relação água extracelular/intracelular; AEC: Água extracelular; AIC: Água intracelular; ACT: Água corporal total; HD: Hidratação; DP: Desvio Padrão. ${ }^{*} p<0,005$.

Tabela 11. Escala de Karnofsky e ângulo de fase, em média (+/-DP) para os grupos avaliados.

\begin{tabular}{ccc}
\hline & Controle & Desnutridos \\
\hline KPS $(\%)$ & $90 \pm 1,7$ & $80 \pm 14,9$ \\
Ângulo de fase $(\stackrel{\circ}{ })$ & $6,3 \pm 07$ & $6,2 \pm 0,4$ \\
\hline
\end{tabular}

KPS: Escala de Karnofsky; DP: Desvio Padrão.

A Tabela 12 mostra as correlações entre as variáveis numéricas da amostra, estão expostas na tabela as correlações com $r>0,5$ e foi considerado nível de significância de $p<0,005$ em todas.

Tabela 12. Correlações significativas entre as variáveis analisadas na amostra.

EMAP (mm): 0,52 (HAND); 0,51 (IMC); 0,63 (IMLG) e 0,52 (ACT)

HAND (kg): 0,52 (EMAP); 0,63 (IMLG); 0,61 (ACT)

$\mathrm{CP}(\mathrm{cm}): 0,72$ (IMC); 0,58 (IMG); 0,62 (ACT)

IMC (kg/m²): 0,51 (EMAP); 0,93 (IMG); 0,93 (ACT)

EMAP: Prega musculo adutor do polegar; HAND: Dinamometria; CP: Circunferencia da panturrilha; IMC: Índice de massa corporal; IMLG: Índice de massa livre de gordura; IMG: Índice de massa gorda ( $\left.\mathrm{kg} / \mathrm{m}^{2}\right)$; ACT: Água corporal total (L); 
Foi aplicado o teste qui-quadrado para verificar a associação das variáveis categóricas entre os grupos, adotando um intervalo de confiança de 95\% e em seguida o teste de regressão logística Odss ratio para avaliar a força de associação destas (Tabela 13). Portando a CP, o IMC, IMG e o nível de hidratação $(H D)$ foram as variáveis que apresentaram diferença significativa entre os grupos e uma força de associação relevante.

\begin{tabular}{lll}
\hline \multicolumn{3}{l}{ Tabela 13. Força de associação para as variáveis categóricas. } \\
\hline Variável & $\mathrm{P}^{*}$ & Odds ratio \\
\hline Sexo & 0,43 & 1,47 \\
EMAP & 1,0 & 1,0 \\
Hand & 0,38 & 1,57 \\
CP & 0,006 & 4,33 \\
Albumina & 0,44 & 0,40 \\
Proteínas totais & 0,57 & 0,63 \\
PCR & 0,81 & 0,89 \\
Local do tumor & 0,28 & 0,50 \\
Estadiamento & 0,10 & 0,31 \\
Presençã de metástase & 0,10 & 1,50 \\
Hidratação & 0,03 & 5,04 \\
IMC & 0,001 & 0,19 \\
IMLG & 0,09 & 0 \\
IMG & 0,001 & 5,00 \\
Ângulo de fase & 0,32 & 4,03 \\
EMAP: Espessura do músculo adutor do polegar; Hand: Dinamometria; CP: Circunferencia da \\
Panturrilha; PCR: Proténa C Reativa; IMC: Índice de Massa Corporal; IMLG: Índice de massa \\
livre de gordura; IMG: Índice de Massa Gorda. *Foi adotado valor significativo de p<0,005.
\end{tabular}

Segundo os testes, os pacientes que obtinham a CP abaixo do ponto de corte apresentaram 4,3 vezes mais chance de estar desnutrido. Já os pacientes que estavam super hidratos possuíam 5 vezes mais chance de estar desnutrido do que os pacientes com hidratação normal ou até desidratados. Segundo o IMC os pacientes que apresentaram IMC menor que o ponto de corte para idosos possuíam $81 \%$ mais chance de estar desnutrido do que os que apresentavam IMC dentro da faixa de eutrofia. E segundo o IMG os pacientes que apresentavam o IMG diminuído tinham 9,2 vezes mais chance de estar desnutrido do que os que apresentavam o IMG normal (Tabela 14). 


\begin{tabular}{lll}
\hline \multicolumn{2}{l}{ Tabela 14. Impacto das variáveis com força de associação relevantes. } \\
\hline Variável & Classificação & Consequência \\
\hline CP & Abaixo & $4,3 \times$ mais chance de ser \\
& & desnutrido \\
IMC & Abaixo & $81 \%$ mais chance de \\
& ser desnutrido \\
IMG & Abaixo & $5 x$ mais chance de ser \\
& Acima & $\begin{array}{l}\text { desnutrido } \\
\text { HD }\end{array}$ \\
& & $\begin{array}{l}5 x \text { mais chance de ser } \\
\text { desnutrido }\end{array}$ \\
\hline
\end{tabular}

CP: Circunferencia da panturrilha; IMC: Índice de massa corporal; IMG: Índice de massa gorda; HD: Hidratação.

Após a comparação entre as médias das variáveis com distribuição normal e não normal, pelos testes t e de Mann-Whitey, foram selecionadas apenas as variáveis independentes que apresentaram relação significativa para serem incluídas no modelo inicial, sendo essas: CP, Hidratação, IMC, IMG, MG (em kg e em \%) Água Corpora Total (ACT), Resistencia, Reatância, KPS, Peso e Água Extra Celular (AEC). Para o cálculo de colinearidade entre as variáveis independentes através do Variance Inflation Factor (VIF) foi adotado valor inferior a 3.

Como várias variáveis possuíram valores acima de 3 , foram removidas as de maior valor e recalculadas até que todas possuíssem valor inferior a 3 , compondo o modelo inicial (Tabela 15).

Tabela 15. Colinearidade das variáveis através do VIF.

\begin{tabular}{ll}
\hline Variável & VIF \\
\hline CP $(\mathrm{cm})$ & 1,65 \\
$\mathrm{HD}(\mathrm{L})$ & 1,37 \\
$\mathrm{IMC}\left(\mathrm{kg} / \mathrm{m}^{2}\right)$ & 2,12 \\
$\mathrm{IMG}\left(\mathrm{kg} / \mathrm{m}^{2}\right)$ & 1,55 \\
$\mathrm{KPS}(\%)$ & 1,70 \\
\hline
\end{tabular}

VIF: Variance inflation fator; CP: Circunferência da panturrilha; HD: Hidratação; IMC: Índice de massa corporal; IMG: Índice de massa gorda; KPS: Escala de Karnofsky. 
O resultado, segundo as análises no contexto multivariado estão descritas na Tabela 16. A partir destas análises, em busca de um modelo "ótimo", foram excluídas as variáveis que não foram significativas, chegando então a um modelo final em que KPS e IMC apresentaram associações significativas no contexto multivariado (Tabela 17). Neste modelo, a cada 1 unidade de KPS diminui em $8 \%$ a chance de ser do grupo de risco e a cada aumento em 1 unidade de IMC diminui 37\% a chance de ser do grupo de risco. Para ambas foi adotado intervalo de confiança de $95 \%$.

Tabela 16. Análises multivariadas das variáveis selecionadas.

\begin{tabular}{lllllll}
\hline Variável & B & S.E. & P & Odss & Maior & Menor \\
\hline CP $(\mathrm{cm})$ & $-0,75$ & 1,64 & 0,64 & 0,47 & 0,19 & 11,71 \\
$\begin{array}{l}\text { Hidratação } \\
\text { (L) }\end{array}$ & 0,45 & 1,37 & 0,73 & 1,58 & 0,10 & 23,44 \\
IMG $\left(\mathrm{mg} / \mathrm{m}^{2}\right)$ & 0,18 & 2,39 & 0,93 & 1,20 & 0,01 & 131,31 \\
& & & & & & \\
$\mathrm{KPS}$ & $-0,19$ & 0,08 & 0,03 & 0,82 & 0,70 & 0,97 \\
$\mathrm{IMC}\left(\mathrm{kg} / \mathrm{m}^{2}\right)$ & $-0,88$ & 0,40 & 0,02 & 0,41 & 0,18 & 0,91
\end{tabular}

CP: Circunferencia da panturrilha; IMG: Índice de massa gorda; KPS: Escala de Karnofsky; IMC: Índice de massa corporal.

\begin{tabular}{|c|c|c|c|c|c|c|}
\hline Variável & $B$ & S.E. & $P$ & Odss & Menor & Maior \\
\hline KPS (\%) & $-0,08$ & 0,03 & 0,01 & 0,91 & 0,85 & 0,98 \\
\hline $\begin{array}{l}\mathrm{IMC} \\
\left(\mathrm{ka} / \mathrm{m}^{2}\right)\end{array}$ & $-0,47$ & 0,14 & 0,00 & 0,62 & 0,47 & 0,82 \\
\hline
\end{tabular}

A partir do modelo final foi gerado a fórmula para aplicação prática (Figura 2) em que $X$ é a probabilidade de se pertencer ao grupo de risco para desnutrição. Caso o resultado seja entre 0,5 e 1,0 o paciente é estimado como grupo de risco, entre 0 e 0,49 o paciente estaria fora de risco.

$$
\mathrm{X}=\frac{1}{1+\mathrm{e}^{-(17,979-0,471 \mathrm{IMC}-0,089 \mathrm{KPS})}}
$$


Figura 3. Equação gerada.

O modelo classificou corretamente $84,7 \%$ da amostra, $80 \%$ do grupo controle e $88,2 \%$ do grupo desnutrido. 


\section{6 - DISCUSSÃO}

$\mathrm{Na}$ etapa preliminar de identificação das variáveis mais importantes para a composição de um instrumento de triagem de risco nutricional para pacientes com câncer em seguimento ambulatorial, algumas variáveis antropométricas, de composição corporal e clínicas, mostraram-se correlacionadas com a desnutrição. Ainda assim, encontrou-se que a combinação das variáveis IMC e KPS em um modelo matemático foi a que melhor mostrou um desempenho estatisticamente significativo na triagem de risco nutricional para o grupo avaliado.

$\mathrm{Na}$ literatura é comum o uso de variáveis antropométricas e de composição corporal associadas a desnutrição, embora alguns estudos ainda apresentem resultados conflitantes. Porem para as variáveis clínicas ainda existem poucas comparações diretamente com a desnutrição, como o KPS, que neste estudo apresentou maior associação com a desnutrição do que algumas variáveis que são mais vistas na literatura. A desnutrição é uma condição muito prevalente em pacientes com câncer, ${ }^{62}$ portanto a associação destes parâmetros, sejam eles, antropométricos, bioquímicos, de composição corporal e/ou clínicos, com a desnutrição ajuda em uma intervenção precoce e na identificação de risco nutricional nestes pacientes. ${ }^{63,64}$

A maioria da amostra não estava realizando tratamento, no momento da coleta deste estudo, como quimioterapia e/ou radioterapia, foi observado que destes pacientes a maioria apresentou tanto apetite como ingestão alimentar preservados. Entretanto, o resultado foi diferente para os pacientes em tratamento, onde a maioria apresentou apetite diminuído e $44 \%$ relataram ingestão alimentar diminuída. Mostrando o reflexo do tratamento oncológico no apetite e na ingestão alimentar, resultado parecido ao de Hiroaki et al (2019) que analisou o efeito da quimioterapia na ingestão alimentar em mulheres com tumores ginecológicos e notou que as pacientes submetidas a este tratamento apresentavam uma menor ingestão alimentar, principalmente de 1 a 3 dias após as sessões. ${ }^{65}$ 
O principal local primário encontrado nos pacientes avaliados foi o câncer que acomete o trato gastrointestinal, principalmente a porção superior. Segundo estimativas do INCA no ano de 2020 a incidência deste tipo de tumor aparece como a terceira no ranking entre homens e mulheres, mostrando sua alta prevalência e gerando preocupação com os novos casos. Estas estimativas também mostraram uma maior prevalência de casos em homens do que nas mulheres, principalmente para o câncer de estomago, resultado parecido ao deste estudo. ${ }^{8}$

Por mais que ainda se estude as causas do câncer, sabemos que 0 estilo de vida contribui para o surgimento de muitos dos casos. Ao longo da vida as pessoas se expõem a situações que podem agravar esse risco, tendo como consequência o aparecimento de algumas doenças, principalmente na população mais idosa. ${ }^{66}$ Este estudo conteve a maioria de sua amostra pacientes com idade mais avançada, e apesar da idade não ter tido forte associação com a desnutrição, alguns estudos mostram que apenas este fator isolado já aumenta o risco do paciente desenvolver a doença e contribui para a piora de seu prognostico, principalmente quando associada à desnutrição, ${ }^{67,68}$ fator que também esteve presente neste estudo, pois grande parte da amostra estava desnutrida, segundo o IMC e também pelo GLIM, onde a maioria dos desnutridos já apresentavam desnutrição grave.

O IMC é uma das variáveis mais estudadas e que apresenta melhor associação com a desnutrição em pacientes com câncer. ${ }^{21} \mathrm{O}$ estudo apresenta grande parte de sua amostra com IMC abaixo do ponto de corte, o que demonstra que mesmo se tratando de uma população de nível ambulatorial o acometimento do estado nutricional é alto. Pensando em um contexto no SUS o acometimento destes pacientes pode-se dar não só pela doença em si, mas também pela demora do diagnóstico e tratamento. Um estudo realizado com mulheres portadoras de câncer do colo do útero mostrou que para as pacientes atendidas no SUS houve demora tanto para o diagnostico quanto para o inicio do tratamento, quando comparadas a atendimentos particulares, o que pode 
levar estes pacientes a já apresentarem um prejuízo no estado nutricional no momento inicial do contato ambulatorial. ${ }^{69}$

Outro resultado que chama a atenção é o alto número de inadequações na quantidade de massa magra e nos baixos índices de massa livre de gordura nos pacientes avaliados. A maioria da amostra apresentou valores significativamente baixos de MLG e IMLG. Quando associamos a MLG com outras medidas antropométricas, de funcionalidade e massa muscular encontramos uma associação positiva entre esta variável com a EMAP e o HAND, mostrando que neste estudo o déficit de MLG pode estar relacionado não só a perda muscular, mas também tem impacto na funcionalidade. Sousa et al (2019) realizou um estudo no Rio Grande do Norte, em pacientes com câncer, adultos e idosos e analisou a massa muscular através de tomografia computadorizada, mostrando que, quando abaixo do ponto de corte, a massa muscular, pode aumentar o risco de mortalidade em pacientes com câncer. ${ }^{70}$

A diminuição da funcionalidade quando associada a perda de MLG e perda de peso pode ainda caracterizar outra condição, a sarcopenia. $O$ consenso europeu de sarcopenia, publicado em 2019, ressalta a importância da associação da MLG e de paramentos de funcionalidade para evitar o diagnostico tardio de sarcopenia e seu risco para o estado nutricional. ${ }^{71}$

A sarcopenia é uma condição muito vista em pacientes com câncer, como encontrado nesta amostra onde 44 pacientes, correspondendo a $61 \%$ da amostra total, apresentava esta condição e também é um fator agravante do estado nutricional, principalmente se tratando de uma população idosa. ${ }^{72}$ Ela é também uma condição muito desfavorável ao prognóstico, principalmente em pacientes com câncer, pois estudos mostram que a diminuição da massa muscular esta associada ao aumento da toxicidade a quimioterapia além de aumentar as chances de recidiva da doença. ${ }^{73,74}$

Devido a MLG estar baixa em praticamente toda a amostra, esta variável não foi discriminatória de desnutrição entre os grupos, porem, nas primeiras análises algumas variáveis de composição corporal demonstraram 
um força de associação relevante a desnutrição, como o IMG e a hidratação. Em nossos achados os pacientes que possuíam o IMG diminuído apresentaram 5,0 vezes mais chances de ser do grupo de risco do que os pacientes com IMG dentro da faixa de normalidade.

Um estudo examinou o efeito da composição corporal na sobrevida de pacientes com câncer gastrointestinal e apresentou resultados semelhantes em que a MG preservada aumentou a sobrevida destes ${ }^{75}$ o que pode ser um fator protetor a estes pacientes, principalmente aos submetidos a intervenções cirúrgicas. Outro estudo realizou uma revisão bibliográfica sobre o impacto da composição corporal em pacientes com câncer abordando o paradoxo da obesidade e demonstrou que, em certas situações, a reserva adiposa dos pacientes serviu como fator protetor, principalmente após o inicio do tratamento. ${ }^{76}$ Porém é importante ressaltar que o acumulo de gordura corporal pode levar a situações que prejudicam o prognóstico do paciente, como a obesidade sarcopênica. Esta condição se caracteriza pela perda de massa muscular simultânea ao acumulo de MG, identificada tanto pelo IMG, quanto pela porcentagem de $M G$, associados à perda de funcionalidade ${ }^{77}$ e vem demonstrando complicações ao tratamento oncológico. Em um estudo realizado na China, pacientes com câncer de estomago e que tinham obesidade sarcopenica apresentaram 5 vezes mais risco de desenvolver complicações pós cirúrgicas. ${ }^{78}$

Quanto a hidratação, grande parte da amostra apresentou inadequações que podem ser advindas do tratamento e fármacos administrados, que em muitas vezes causam alterações hemodinâmicas que podem gerar complicações. ${ }^{79}$ No caso deste estudo os pacientes hiper hidratados, apresentaram 5 vezes mais chance de ser do grupo de risco do que os com hidratação normal.

Um estudo avaliou a ingestão hídrica de pacientes com câncer durante a internação e mostrou que na maioria das vezes o consumo não passava de um litro por dia e que mesmo depois da internação os pacientes apresentam dificuldades na ingestão hídrica, não ultrapassando dois litros por dia. ${ }^{80} \mathrm{O}$ que 
pode sugerir que a hiper-hidratação da amostra provém do tratamento recebido e não necessariamente da ingestão, tornando o tratamento oncológico e a medicação um fator de risco ao estado nutricional deste grupo. ${ }^{81}$ Noda et al (2020) avaliou, em pacientes com câncer de pulmão, a associação da hiperhidratação, medida pela relação entre a ACT e a AEC com a durabilidade da quimioterapia e sucesso do tratamento e encontrou que os pacientes com a relação ACT/AEC maior ou igual a 0,4 apresentaram mais tempo de tratamento e piores prognósticos. ${ }^{82}$

Outras duas variáveis que apresentaram força de associação relevante nas primeiras analises foram a CP e o IMC, que são parâmetros mais conhecidos e mais estudadas na avaliação de risco para a desnutrição, que as anteriores. O IMC, como já citado, é uma das principais ferramentas que auxiliam os profissionais a classificarem o estado nutricional. Em pacientes com câncer o IMC abaixo de $18,5 \mathrm{~kg} / \mathrm{m}^{2}$ e acima de $30 \mathrm{~kg} / \mathrm{m}^{2}$ aumenta a chance de complicações pós operatórias, segundo um estudo que avaliou a influencia da desnutrição, no pós operatório de pacientes com câncer de bexiga. ${ }^{83} \mathrm{O}$ IMC baixo está associado a desnutrição e esta condição traz agravantes para as medidas terapêuticas no câncer, na qualidade de vida do paciente e na piora do prognostico, ${ }^{84}$ mas o IMC acima dos pontos de corte também reflete em risco para desenvolvimento de alguns tipos de câncer. Um estudo nos Estados Unidos, realizado com 99.039 mulheres na pré menopausa, mostrou que as mulheres com IMC acima de $25 \mathrm{~kg} / \mathrm{m}^{2}$ apresentavam maior risco para desenvolvimento de câncer de mama, quando comparadas a mulheres na faixa de eutrofia. ${ }^{85}$

Han, et al (2019) investigou a relação entre o IMC e aspectos clínicospatológicos e prognóstico em 788 pacientes com câncer gástrico, o estudo encontrou que o IMC teve relação com o estado nutricional, proporção de metástase e acometimento de linfonodos e tempo operatório, além de mostrar que os pacientes com baixo IMC apresentaram sobrevida menor do que aos pacientes com IMC normal ou aumentado. ${ }^{86}$ Alguns destes resultados foram 
semelhantes ao deste estudo ao encontrarem não só relação do IMC com o estado nutricional mas também com a proporção de metástase.

Porem a literatura demonstra que o uso isolado do IMC pode causar alguns equívocos, por não avaliarem a composição corporal do paciente de forma detalhada, em compartimentos corporais, como faz, por exemplo, um exame de bioimpedância. ${ }^{87,88}$

Neste contexto surgem outros meios que auxiliam no entendimento do estado nutricional, e que quando associadas a ferramentas como o IMC, conseguem sinalizar de forma mais efetiva o estado destes pacientes como é o caso da CP, que segundo as analises deste estudo contribui em 4,3 vezes mais chance do paciente estar em risco nutricional quando seus valores estão abaixo do ponto de corte. Landi et al.,2014 realizou um estudo e avaliou a relação da CP com a funcionalidade e força muscular em idosos com mais de 80 anos e demonstrou que, em seu estudo, a CP foi um bom marcador de prognostico e de rastreio para sarcopenia. ${ }^{89}$

Estudos associando a CP com demais parâmetros antropométricos para analise do estado nutricional tem ganhado força nos últimos anos, não só pelo seus resultados mas também pela CP ser um método fácil, rápido, não invasivo e de baixo custo, sendo de fácil aplicação na prática clínica. ${ }^{90,91,92}$ Sousa et al (2020) em seu estudo realizado no Brasil com 250 pacientes, analisou o impacto da CP no prognostico de pacientes com câncer e concluiu, assim como este estudo, que a CP tem associação com a desnutrição e que quando diminuída pode aumentar o risco de mortalidade nestes pacientes. ${ }^{93}$

Melo et al (2016) mostrou associações de CP com IMC e o risco de mortalidade em idosos internados. Os que possuíam IMC baixo combinado com CP diminuída apresentaram maior mortalidade. ${ }^{94} \mathrm{Em}$ nosso grupo amostral o IMC e a CP apresentavam-se diminuídos principalmente no grupo desnutrido, o que nas, primeiras analises, mostrou que estes fatores, quando abaixo do ponto de corte, aumentam o risco nutricional, como exposto nos artigos citados. 
Algumas variáveis, não apresentaram associação relevante com a desnutrição em nenhum momento e também não foram diferentes entre os grupos desnutridos e controle, como foi o caso dos marcadores bioquímicos como PCR, albumina e proteínas totais. Na maioria da amostra estes marcadores encontraram-se dentro dos padrões de normalidade, por se tratar de pacientes em atendimento ambulatorial acredita-se que estes marcadores e o estado nutricional estejam melhores, se comparados a pacientes internados, que podem estar mais debilitados que os pacientes em nível ambulatorial.

Um estudo realizado com pacientes portadores do vírus HIV (Vírus da Imunodeficiência Humana) comparou o estado clínico e nutricional de pacientes internados com os em seguimento ambulatorial e encontrou que os pacientes internados apresentavam pior estado nutricional. ${ }^{95}$ Forbes, et al (2020) analisou o perfil bioquímico de pacientes com retocolite ulcerativa e encontrou níveis de albumina menores nos pacientes internados do que nos em seguimento ambulatorial, evidenciando uma provável piora no perfil bioquímico em pacientes na enfermaria. ${ }^{96}$

Apesar disso vale ressaltar a importância destas variáveis que podem auxiliar no entendimento do estado nutricional. Mesmo que se demonstrem mais afetados em pacientes internados, não devemos deixar de observar estes parâmetros para análise do estado nutricional. A PCR, por exemplo, por ser um marcador inflamatório pode auxiliar no diagnóstico de caquexia, condição frequentemente encontrada com pacientes com câncer. ${ }^{97} \mathrm{~A}$ albumina também é um marcador importante no prognostico de pacientes com câncer. Apesar da amostra deste estudo não apresentar altas taxas de inadequações nestes parâmetros, pelos possíveis motivos citados anteriormente, é importante destacar a relevância da albumina neste contexto. Um estudo realizado em Uberlândia (MG) observou o efeito da albumina baixa na mortalidade de pacientes com câncer internados e concluiu que esta fora um dos preditores de mortalidade nestes pacientes. ${ }^{98}$

A EMAP e o HAND são variáveis que também não apresentaram associação com a desnutrição neste estudo, embora apresentem resultados 
diferentes em outros estudos, ${ }^{99,100}$ como o de Valente et al (2016) que encontrou em seu estudo associação significativa entre a EMAP e o estado nutricional dos pacientes, avaliado pela avaliação subjetiva global, em pacientes com câncer. ${ }^{101}$ Quanto ao HAND o próprio Consenso Europeu de Sarcopenia inclui esta variável como importante na averiguação do estado nutricional. ${ }^{71}$

Outros estudos encontraram resultados parecidos ao deste estudo ao não encontrarem relação do HAND ao riso nutricional de seus pacientes. Um estudo realizado em 2020 na Austrália com 246 pacientes em tratamento de câncer também concluiu que o HAND não foi um marcador satisfatório para o risco do estado nutricional e de mortalidade. ${ }^{26}$ Byernes et al. (2018), também apresentou um resultado parecido ao comparar o HAND com instrumentos de triagem já validados, como o Malnutrition Screening Tool (MST) e a Avaliação Subjetiva Global produzida pelo próprio paciente (ASG-PPP) e também não identificou o HAND como ferramenta de precisão para avaliar a desnutrição em pacientes cardiopatas cirúrgicos. ${ }^{102}$ Estes estudos contém um ponto em comum com os resultados deste, pois ambos destacam a dificuldade em analisar a funcionalidade de pacientes sem pontos de corte específicos e em populações diferentes, além de ressaltarem a diferença destes resultados em pacientes internados com os em acompanhamento ambulatorial, pois a maioria dos artigos citados neste estudo, em que o HAND e o EMAP obtiveram relação com risco nutricional, foram realizados em pacientes internados.

O KPS é uma escala de funcionalidade muito utilizada em pacientes com câncer. A literatura vem demonstrando sua eficácia como marcador de prognostico e de funcionalidade, destacando sua importância para avaliação do estado nutricional, visto que, qualidade de vida e funcionalidade são fatores que tem grande impacto no estado nutricional dos pacientes. ${ }^{103,104,105}$

Apesar de poucos estudos relacionando diretamente o KPS com a desnutrição, alguns estudos associam o impacto desta variável no estado nutricional. Modesto, et al (2018) realizou um estudo no Brasil com pacientes em dialise peritoneal e avaliou a variação do KPS de pacientes com doença 
renal crônica por 12 meses, encontrando que o KPS pode de ser um bom preditor de mortalidade. ${ }^{106}$ Outro estudo realizado em 2020 na Alemanha, que contou com 539 pacientes com câncer de pulmão, tinha como objetivo associar o estado nutricional, que foi aferido pelo Controlling Nutritional Status (CONUT) e o Prognostic Nutritional Index (PNI) com o prognostico destes pacientes e observou que pacientes com KPS abaixo de $80 \%$, média do KPS no grupo desnutrido em nosso estudo, se associaram a um pior estado nutricional. ${ }^{107} \mathrm{O}$ KPS e o estado nutricional são fatores importantes para mensuração do prognostico em pacientes com câncer, ${ }^{108}$ por isso a relação entro KPS e estado nutricional é muito importante.

Neste estudo o KPS foi uma das variáveis que mais se associou a desnutrição em pacientes assistidos em ambulatório e ao realizar a coleta de dados foi observado que a avaliação do KPS esteve mais presente nos prontuários médicos de atendimento ambulatorial do que no atendimento em enfermarias, mostrando que esta ferramenta além de rápida e fácil aplicação também é aplicável em nível ambulatorial.

Entretanto mais estudos são necessários para avaliar o efeito do KPS diretamente associado ao estado nutricional, na sua evolução ou prognostico.

Para a identificação do risco nutricional e o diagnóstico de desnutrição deve-se levar em conta um conjunto de fatores e variáveis, utilizados de forma integrada. ${ }^{109,110}$ Este estudo utilizou como critério diagnostico para desnutrição o critério GLIM, que conta com o uso de variáveis combinadas, como ingestão alimentar, gravidade da doença, medidas antropométricas e de composição corporal, além da inclusão de uma variável de funcionalidade. Como limitação, a ferramenta não foi validada para população brasileira, mas ainda assim, alguns estudos já trabalham com a validação destes critérios e estes vêm se apresentando como uma ferramenta mais completa para um diagnóstico do estado nutricional..$^{25}$

Bolívar et al. (2019) realizou um estudo com 282 pacientes em tratamento oncológico com o objetivo de comparar os critérios de diagnóstico 
de desnutrição entre o GLIM e critérios já validados como a Avaliação Subjetiva Global - Produzida pelo Próprio Paciente (ASG-PPP) e estabelecer a associação do GLIM com a mortalidade em pacientes com câncer de pulmão, o estudo mostrou que o critério GLIM teve acurácia parecida ao da ASG-PPP ao diagnosticar desnutrição e predizer a mortalidade para estes pacientes. ${ }^{111} \mathrm{De}$ Groot et al. (2020) apresentou resultados parecido em seu estudo, que contou com 426 pacientes em tratamento oncológico na Austrália e tinha como objetivo validar o GLIM também utilizando a ASG-PPP como referencia para diagnostico de desnutrição. O estudo concluiu que o critério GLIM também apresentou acurácia, sensibilidade e especificidade ao diagnosticar desnutrição, quando compara a critérios já validados. ${ }^{26}$

O detrimento do estado nutricional em pacientes com câncer é uma realidade prevalente tanto nas enfermarias quanto em ambulatórios. A detecção precoce do risco nutricional auxilia o profissional a ter uma conduta mais assertiva e tem impacto direto na qualidade de vida do paciente. Instrumentos de triagem são uma estratégia que auxilia na detecção do risco nutricional e portanto devem apresentar resultados validos e seguros. ${ }^{112}$

Quando realizado a triagem nesta amostra para divisão dos grupos controle e desnutridos, foi observado que todos os pacientes em risco nutricional, segundo o instrumento de triagem utilizado (NRS-2002), na verdade já estavam desnutridos, a maioria em desnutrição grave, mostrando não só a importância de fazer triagem mas também a importância de, após detecção do risco, realizar uma analise complementar com a finalidade de diagnosticar e classificar corretamente a desnutrição. A aplicação de um instrumento de triagem nutricional seguida por uma analise mais completa do paciente em que se detecta risco é uma estratégia, para avaliação do estado nutricional, cada vez mais defendida pelas principais entidades de nutrição que estudam a desnutrição.

Um ponto positivo do estudo é a utilização de várias variáveis para a associação com a desnutrição, dentre elas variáveis antropométricas, de funcionalidade, bioquímicas, de composição corporal e clinicas. O tamanho 
amostral foi uma das limitações para algumas das análises estatísticas, bem como a composição corporal mais afetada pelo câncer para boa parte dos pacientes avaliados. 


\section{7 - CONCLUSÃo}

A desnutrição esteve presente em $56 \%$ dos pacientes analisados e 0 grupo de desnutridos apresentou maior frequência de sarcopenia, pior KPS e menores valores de dinamometria, peso, massa gorda e muscular;

As variáveis que mais apresentaram força de associação significativa com a desnutrição foram a $\mathrm{CP}$, Hidratação, IMC, IMG, MG (em kg e em \%), ACT, Resistencia, Reatância, KPS, Peso e AEC. Após análises multivariadas e de covariância as variáveis que mais apresentaram associação com a desnutrição foram IMC e o KPS, compondo assim o modelo final. A equação matemática gerado foi assertiva em $84 \%$ dos testes.

O instrumento de triagem criado, com variáveis de fácil aquisição no atendimento ambulatorial, poderá ser muito útil na percepção de quais casos devem ser priorizados pela equipe de nutrição, mas estudos de validação em grupo amostral adequado serão necessários antes de sua incorporação para o uso na prática clínica. 


\section{8 - REFERÊNCIAS BIBLIOGRÁFICAS}

1 - BARBOSA, Camila Milena. A avaliação nutricional como fator interveniente na redução da prevalência de desnutrição hospitalar. 2020. Monografia (Bacharelado em Nutrição) - Faculdade de Ciências da Educação e Saúde, Centro Universitário de Brasília, Brasília, 2020.

2 - CEDERHOLM, T. et al. ESPEN guidelines on definitions and terminology of clinical nutrition. Clinical Nutrition, v.36, n.1, p. 49-64, 2017.

3 - CARO, M.M. et al. Nutritional intervention and quality of life in adult oncology patients. Clinical Nutrition, v.26, p.289-301, 2007.

4 - MOREIRA, J. C.; WAITZBERG, D. L. Consequências funcionais da Desnutrição. Nutrição oral, enteral e parenteral na prática clínica. São Paulo: Atheneu, 2000. p. 399-410.

5 - ARENDS, J. et al. ESPEN expert group recommendations for action against cancer-related malnutrition. Clinical Nutrition, v.36, n.5, p.1187-1196, 2017.

6 - INCA - Instituto Nacional de Câncer. O que é câncer ¿. Disponível em: https://www.inca.gov.br/o-que-e-cancer. Acesso em: 29 mar. 2021.

7 -WELLS, J. C. et al. The double burden of malnutrition: aetiological pathways and consequences for health. The Lancet, v. 395, n. 10217, p. 75-88, 2020.

8 - BRASIL. Ministério da Saúde. Estima 2020: incidência de câncer no Brasil. Instituto Nacional de Câncer José Alencar Gomes da Silva. Rio de Janeiro: INCA; $2020 . \quad$ Disponível em: https://www.inca.gov.br/sites/ufu.sti.inca.local/files//media/document//estimativa -2020-incidencia-de-cancer-no-brasil.pdf. Acesso em: 22 jan. 2021.

9 - NIGHTINGALE, Ginah; SKONECKI, Emily; BOPARAI, Manpreet K. Polypharmacy in Older Adults with Cancer: Evaluating Polypharmacy as Part of the Geriatric Assessment. Current Geriatrics Reports, v. 6, n. 4, p. 219-230, 2017.

10 - ZHANG, X.; EDWARDS, B. J. Malnutrition in Older Adults with Cancer. Current Oncology Reports, v. 21, n. 9, 2019.

11 - BRASIL. Ministério da Saúde. Consenso Nacional de Nutrição Oncológica. Instituto Nacional de Câncer José Alencar Gomes da Silva. Rio de Janeiro: INCA; $2016 . \quad$ Disponível em: https://www.inca.gov.br/sites/ufu.sti.inca.local/files//media/document//consensonutricao-oncologica-vol-ii-2-ed-2016.pdf. Acesso em: 20 jan. 2021. 
12 - YILMAZ, M. et al. The effect of malnutrition on mortality in hospitalized patients with hematologic malignancy. Support Care Cancer, v.28, n.3, p.14411448, 2020.

13 - FEARON, K. et al. Definition and classification of cancer cachexia: an international consensus. Lancet Oncology, v.12, n.5, p.489-495, 2011.

14 - DUNNE, R. F. et al. Characterizing cancer cachexia in the geriatric oncology population. Journal of Geriatric Oncology, v. 10, n. 3, p. 415-419, 2019.

15 - JANSSEN, I. The epidemiology of sarcopenia. Clinics in Geriatric Medicine, v.27, n.3, p.355-363, 2011.

16 - PRADO, C. m. et al. Sarcopenia as a determinant of chemotherapy toxicity and time to tumor progression in metastatic breast cancer patients receiving capecitabine treatment. Clinical Cancer Research, v.15, n.8, p.2920-2926, 2009.

17 - OTTEN, L. et al. Impact of sarcopenia on 1-year mortality in older patients with cancer. Age and Ageing, v. 48, n. 3, p. 413-418, 2019.

18 - MAYR, R. et al. Sarcopenia as a comorbidity-independent predictor of survival following radical cystectomy for bladder cancer. J Cachexia Sarcopenia Muscle, v.9, n.3, p.505-5013, 2018.

19 - BRASIL. Portaria o 1.220, de 3 de junho de 2014. Dispõe sobre a aplicação da Lei no 12.732, de 22 de novembro de 2012, que versa a respeito do primeiro tratamento do paciente com neoplasia maligna comprovada, no âmbito do Sistema Único de Saúde (SUS). Diário Oficial da União 2014.

20 - CABRAL, A. L. et al. Social vulnerability and breast cancer: Differentials in the interval between diagnosis and treatment of women with different sociodemographic profiles. Ciencia e Saude Coletiva, v. 24, n. 2, p. 613-622, 2019.

21 - DALLACOSTA, F. M. et al. Avaliação nutricional de pacientes com câncer em atendimento ambulatorial. Cogitare Enfermagem. v. 22, n. 4, 2017.

22 - WHITE, J. V. et al. Consensus statement: Academy of nutrition and dietetics and American society for parenteral and enteral nutrition: Characteristics recommended for the identification and documentation of adult malnutrition (undernutrition). Journal of Parenteral and Enteral Nutrition, v. 36, n. 3, p. 275-283, 2012.

23 - CEDERHOLM, T. et al. Diagnostic criteria for malnutrition e an ESPEN consensus statement. Clinical Nutrition, v.34, p.335-340, 2015. 
24 - JEEJEEBHOY, K. N. et al. Nutritional assessment: Comparison of clinical assessment and objective variables for the prediction of length of hospital stay and readmission. American Journal of Clinical Nutrition, v. 101, n. 5, p. 956965, 2015.

25 - CEDERHOLM, T., \& JENSEN, G. L. To create a consensus on malnutrition diagnostic criteria: A report from the Global Leadership Initiative on Malnutrition (GLIM) meeting at the ESPEN Congress 2016. Clinical Nutrition, v.36, n.1, p.710, 2017.

26 - DE GROOT, L. M. et al. Malnutrition screening and assessment in the cancer care ambulatory setting: Mortality predictability and validity of the patient-generated subjective global assessment short form (PG-SGA SF) and the GLIM criteria. Nutrients, v. 12, n. 8, p. 1-13, 2020.

27 - BARBOSA, M.R.P. Desempenho de Testes de Rastreamento e Avaliação Nutricional como Preditores de Desfechos Clínicos Negativos em Pacientes Hospitalizados. [Tese]. São Paulo. Faculdade de Medicina da Universidade de São Paulo, 2010.

28 - KOREN-HAKIM, T. et al. Comparing the adequacy of the MNA-SF, NRS2002 and MUST nutritional tools in assessing malnutrition in hip fracture operated elderly patients. Clinical Nutrition, v. 35, n. 5, p. 1053-1058, 2016.

29 - ELIA, M.; ZELLIPOUR, L.; STRATTON, R. J. To screen or not to screen for adult malnutrition? Clinical Nutrition, v. 24, n. 6, p. 867-884, 2005.

30 - WEEKS, C. E.; EMERY, P. W. The development validation and reliability of a nutrition screening tool based on the recommendations of the British Association for Parenteral and Enteral Nutrition (BADEN). Clinical Nutrition, v.23, p.1104-1112, 2004.

31 - MALONE, A.; HAMILTON, C. The Academy of Nutrition and Dietetics/the American Society for Parenteral and Enteral Nutrition consensus malnutrition characteristics: application in practice. Nutrition in Clinical Practice, v.28, n.6, p.639-650, 2013.

32 - VELLAS, B. et al. Overview of the MNA--Its history and challenges. J Nutr Health Aging, v.10, n.6, p.456-465, 2006.

33 - DETSKY, A. S. et al. What is subjective global assessment of nutritional status? J Parenter Enteral Nutrition, v.11, n.1, p8-13, 1987.

34 - KONDRUP, J. et al. Nutritional risk screening (NRS 2002): A new method based on an analysis of controlled clinical trials. Clinical Nutrition, v. 22, n. 3, p. 321-336, 2003. 
35 - FERGUSON, et al. Development of a valid and reliable malnutrition screening tool for adult acute hospital patients. Nutrition. v.15, n.6, p.458-464, 1999.

36 - CAWOOD, A. L. et al. Malnutrition self-screening by using MUST in hospital outpatients: validity, reliability, and ease of use. Am J Clin Nutrition, v.96, p.5, p.1000-1007, 2012.

37 - ÁLVARO SANZ, E. et al. Nutritional risk and malnutrition rates at diagnosis of cancer in patients treated in outpatient settings: Early intervention protocol. Nutrition, v. 57, p. 148-153, 2019.

38 - ARRIBAS, L. et al. NUTRISCORE: A new nutritional screening tool for oncological outpatients. Nutrition, v. 33, p. 297-303, 2017.

39 - GABRIELSON, D. K. et al. Use of an Abridged Scored Patient Subjective Global Assessment (abPG-SGA) as a NutritionalScreening Tool for Cancer Patients in na Outpatient Setting. Nutr. Cancer, v.65, n.2, p.234-239, 2013.

40 - KARNOFSKY, D.A.; BURCHENAL, J.H. The clinical evaluation of chemotherapeutic agents in cancer. Columbia University Press, New York, 1949.

41 - PÉUS, D.; NEWCOMB, N.; HOFER, S. Appraisal of the Karnofsky Performance Status and proposal of a simple algorithmic system for its evaluation. BMC Medical Informatics and Decision Making, v. 13, n. 1, 2013.

42 - TIMMERMANN, C. "Just give me the best quality of life questionnaire": The Karnofsky scale and the history of quality of life measurements in cancer trials. Chronic Illness, v. 9, n. 3, p. 179-190, 2013.

43 - ALI, S. et al. Change in serum albumin level predicts short-term complications in patients with normal preoperative serum albumin after gastrectomy of gastric cancer. ANZ Journal of Surgery, v.89, n.8, p.297-301, 2019.

44 - ADEJUMO, O. L.; KOELLING T. M.; HUMMEL, S.L. Nutritional Risk Index predicts mortality in hospitalized advanced heart failure patients. $J$ Heart Lung Transplant, v.34, n.11, p.1385-1389, 2015.

45 - SHEPHERD, J. A. et al. Body composition by DXA. Bone, v. 104, n. 2016, p. 101-105, 2017.

46 - CHUMLEA, W. C. et al. Body composition estimates from NHANES III bioelectrical impedance data. International Journal of Obesidy, v.26, n.12, p.1596-1609, 2002. 
47 - LEANDRO-MERHI, V. A.; DE AQUINO, J. L. B.; REIS, L. O. Predictors of Nutritional Risk According to NRS-2002 and Calf Circumference in Hospitalized Older Adults with Neoplasms. Nutr Cancer, v.69, n.8, p.1219-1226, 2017.

48 - VALENTE, K. P. et al. Association of adductor pollicis muscle thickness and handgrip strength with nutritional status in cancer patients. PLOS ONE, v. 14, n. 8, p. 1-12, 2019.

49 - JONES, J. M. Development of a nutritional screening or assessment tool using a multivariate technique. Nutrition, v. 20, n. 3, p. 298-306, 2004.

50 - KYLE, U. G. et al. Bioelectrical impedance analysis - Part I: Review of principles and methods. Clinical Nutrition, v. 23, n. 5, p. 1226-1243, 2004.

51 - SCHUTZ, Y.; KYLE, U. U.G.; PICHARD, C. Fat-free mass index and fat mass index percentiles in caucasians aged 18-98 y. International Journal of Obesity, v. 26, n. 7, p. 953-960, 2002.

52 - BROERS, N. J.H. el. Three compartment bioimpedance spectroscopy in the nutritional assessment and the outcome of patients with advanced or end stage kidney disease: What have we learned so far? Hemodialysis International, v. 24, n. 2, p. 148-161, 2020.

53 - MOISSL, U. M. et al. Body fluid volume determination via body composition spectroscopy in health and disease. Physiological Measurement, v. 27, n. 9, p. 921-933, 2006.

54 - WORLD HEALTH ORGANIZATION. Obesity: preventing and managing the global epidemic: report of a WHO Consultation on Obesity, Geneva, 1997. Disponível em: https://apps.who.int/iris/handle/10665/63854. Acesso em:1 mar. 2021.

55 - WORLD HEALTH ORGANIZATION. Physical Status : the Use and Interpretation of Anthropometry. Genova, 1995. Disponível em: https://www.who.int/childgrowth/publications/physical_status/en/. Acesso em: 1 mar. 2021.

56 - ORGANIZACIÓN PANAMERICANA DE LA SALUD. Encuesta Multicéntrica. Salud Bienestar y envejecimento (SABE) en América Latina y el Caribe. Screening, p. 22, 2001

57 - LAMEU, E. et al. Adductor pollicis muscle: a new anthropometric parameter. Rev Hosp Clin Fac Med Sao Paulo. v.59, n.2, p.57-62, 2004.

58 - BRAGAGNOLO, R. et al. Espessura do músculo adutor do polegar: um método rápido e confiável na avaliação nutricional de pacientes cirúrgicos. Revista do Colégio Brasileiro de Cirurgiões, v. 36, n. 5, p. 371-376, Out 2009. 
59 - BARBOSA-SILVA, T. G et al. Prevalence of sarcopenia among communitydwelling elderly of a medium-sized South American city: Results of the COMO VAl? Study. J Cachexia Sarcopenia Muscle, v.7, n.2, p.136-143, 2016.

60 - SCHLÜSSEL, M. M.; DOS ANJOS, L. A.; KAC, G. Hand grip strength test and its use in nutritional assessment. Revista de Nutricao, v. 21, n. 2, p. 223235, 2008.

61 - DODDS, R. M. et al. Grip strength across the life course: Normative data from twelve British studies. PLOS ONE, v. 9, n. 12, p. 1-15, 2014.

62 - COLLING, C.; DUVAL, P. A.; SILVEIRA, D. H. Pacientes Submetidos à Quimioterapia: Avaliação Nutricional Prévia. Revista Brasileira de Cancerologia, v. 58, n. 4, p. 611-617, 31 dez. 2012.

63 - FERREIRA, D. et al. Aceitação de dietas hospitalares e estado nutricional entre paciente com câncer. Einstein (São Paulo), v.11, n.1, p. 41-46, 2013.

64 - BRASIL. Ministério da Saúde. Instituto Nacional de Câncer. Consenso nacional de nutrição oncológica. Rio de Janeiro: Instituto Nacional de Câncer; 2015.

65 - KOMATSU, H. et al. Evaluating Chemotherapy-induced Nausea and Vomiting and Food Intake in Patients With Gynecologic Cancer. Anticancer Res. v.39, n.8, p.4555-4560, 2019.

66 - MISLANG, A.R. et al. Nutritional management of older adults with gastrointestinal cancers: An International Society of Geriatric Oncology (SIOG) review paper. J Geriatr Oncol, v.9, n.4, p.382-392, jul. 2018 . Disponível em: . Acesso em: 22 jun. 2021.

67 - DE PINHO, N.B. et al. High prevalence of malnutrition and nutrition impact symptoms in older patients with cancer: Results of a Brazilian multicenter study. Câncer, v.126, n.1, p.156-164, 1 jan. 2020.

68 - LACAU ST GUILY, J. et al. NutriCancer: A French observational multicentre crosssectional study of malnutrition in elderly patients with cancer. Journal of geriatric oncology, v.9, n.1, p.74-80, jan. 2018.

69 - SANTANA, PM. Retardo do tratamento de mulheres com câncer do colo do útero. Rio de Janeiro; 2016. [Dissertação de Mestrado-Fundação Oswaldo Cruz].

70 - SOUSA, I. M. Massa muscular esquelética de pacientes com câncer: comparação entre métodos de avaliação e associação com mortalidade. 2019. 55f. Tese (Programa de PósGraduação em Nutrição) - Universidade Federal do Rio Grande do Norte, Natal, 2019. 
71 - CRUZ-JENTOFT, A. J. et al. Sarcopenia: Revised European consensus on definition and diagnosis. Age and Ageing, v. 48, n. 1, p. 16-31, 2019.

72 - BRAVO, J. P. et al. Prevalence of sarcopenia and associated factors in institutionalised older adult patients. Clin Nutr ESPEN. v.27, p. 113-119, 2018.

73 - RIER, H. N. e et al. The Prevalence and Prognostic Value of Low Muscle Mass in Cancer Patients: A Review of the Literature. The Oncologist, v. 21, n. 11, p. 1396-1409, 2016.

74 - HU, X. e et al. Sarcopenia predicts prognosis of patients with renal cell carcinoma: A systematic review and meta-analysis. International Braz J Urol, v. 46, n. 5, p. 705-715, 2020.

75 - BLACK, D. et al. Prognostic Value of Computed Tomography: Measured Parameters of Body Composition in Primary Operable Gastrointestinal Cancers. Annals of Surgical Oncology, v. 24, n. 8, p. 2241-2251, 2017.

76 - STRULOV, S. S et al. The Obesity Paradox in Cancer-Moving Beyond BMI. Cancer Epidemiol Biomarkers Prev, v. 26, n.1, p. 13-16, 2017.

77 - POLYZOS, S. A.; MARGIORIS, A.N. Sarcopenic obesity. Hormones (Athens), v.17, p.321-331, 2018.

78 - LOU, N. et al. Sarcopenia in overweight and obese patients is a predictive factor for postoperative complication in gastric cancer: a prospective study. Eur J Surg Oncology, v.43, n.1, p.188-195, 2017.

79 - ALBINI, A. e et al. Cardiotoxicity of anticancer drugs: The need for cardiooncology and cardio-oncological prevention. Journal of the National Cancer Institute, v. 102, n. 1, p. 14-25, 2010.

80 - TORRES, A. L. C. DICCINI, S. Constipação intestinal em pacientes com tumores intracranianos. Revista Latino-Americana de Enfermagem, v. 14, n. 3, p. 397-404, 2006.

81 - SILVA, P. B. et al. Controle dos sintomas e intervenção nutricional. fatores que interferem na qualidade de vida de pacientes oncológicos em cuidados paliativos. Rev. dor, v. 11, n. 4, p. 282-288, 2010.

82 - NODA, Y. et al. Association Between Extracellular Water-to-Total Body Water Ratio and Therapeutic Durability for Advanced Lung Cancer. Anticancer Res. v. 40, n.7, p.3931-3937, 2020.

83 - SWALARZ, M. et al. Correlation between malnutrition, body mass index and complications in patients with urinary bladder cancer who underwent radical cystectomy. Adv Clin Exp Med. v.27, n.8, p.1141-1147, 2018. 
84 - MARSHALL, K. M. et al. Prevalence of malnutrition and impact on clinical outcomes in cancer services: A comparison of two time points. Clin Nutr. v.38, n.2, p.644-651, 2019.

85 - AHN, J. et al. Adiposity, adult weight change, and postmenopausal breast cancer risk. Arch Intern Med. v.167, p.2091-2102, 2007.

86 - HAN, B. L. et al. Relationship between body mass index and clinicopathological characteristics and prognosis of gastric cancer patients. Zhonghua Zhong Liu Za Zhi, v.41, n.7. p.527-532, 2019.

87 - LI, X. T. et al. Visceral and subcutaneous fat as new independent predictive factors of survival in locally advanced gastric carcinoma patients treated with neo-adjuvant chemotherapy. J Cancer Res Clin Oncol. v. 141 p. 1237-1247, 2015.

88 - NATIONAL COMPREHENSIVE CANCER NETWORK. Clinical practice Guidelines in Oncology Gastric Cancer. Disponível em : https://www.nccn.org/professionals/ physician_gls/pdf/gastric.pdf. Acesso em: 22 jan. 2021.

89 - LANDI, F. et al. Calf circumference, frailty and physical performance among older adults living in the community. Clinical Nutrition, v. 33, n. 3, p. 539544, 2014.

90 - TOSATO, M. et al. Measurement of muscle mass in sarcopenia: from imaging to biochemical marker. Aging Clin Exp Res., v. 29, n. 1, p. 19-27, 2017.

91 - MERHI, L.-, Predictors of nutritional risk according to NRS-2002 and calf circumference in hospitalized older adults with neoplasms Nutr Cancer, v.69, n.8, p. 1219-1226, 2017.

92 - REAL, G. G. et al. Calf Circumference: A Marker of Muscle Mass as a Predictor of Hospital Readmission. Journal of Parenteral and Enteral Nutrition, v. 42, n. 8, p. 1272-1279, 2018.

93 - SOUSA, I. M. et al. Low calf circumference is an independent predictor of mortality in cancer patients: a prospective cohort study. Nutrition, v. 79-80, p. 1-7, 2020.

94 - MELLO, F. S.; WAISBERG, J.; SILVA, M. D. L. D. N. Circunferência da panturrilha associa-se com pior desfecho clínico em idosos internados. Geriatrics Gerontology and Aging. v. 10, n 2, p. 80-85, 2016.

95 - SURUAGY, C. M. I. et al. Nutritional indicators in patients with HIV/AIDS: Ambulatorial and hospital reality. Nutricion Clinica y Dietetica Hospitalaria, v. 38, n. 1, p. 122-127, 2018. 
96 - FORBES, A. Nutrition and inflammatory bowel disease. Current opinion in clinical nutrition and metabolic care, v. 23, n. 5, p. 350-354, 2020.

97 - SILVA, J.B. et al. The relationship between nutritional status and the Glasgow prognostic score in patients with cancer of the esophagus and stomach. Nutr Cancer. v.65, n.1, p. 25-33, 2013.

98 - LIMA, Emanuelle do Nascimento Santos. FERREIRA, Isabela Borges. SILVA, Nayara Cristina da. PRESTES, Isaías Valente. Albumina sérica é preditor independente de mortalidade hospitalar em pacientes com câncer, 2018. 25 f. Trabalho de Conclusão de Residência(Residência Ciências da Saúde) - Universidade Federal de Uberlândia, 2018.

99 - BRAGAGNOLO, R. et al. Espessura do músculo adutor do polegar: Um método rápido e confiável na avaliação nutricional de pacientes cirúrgicos. Revista Colégio Brasileiro de Cirurgiões. v. 36 n. 5, p. 371-376, 2009.

100 - FLOOD, A. et al. The use of hand grip strength as a predictor of nutrition status in hospital patients. Clin Nutr, v. 33, n. 1, p. 106-114, fev. 2014.

101 - VALENTE, Katarina Papera e colab. Thickness of the adductor pollicis muscle in nutritional assessment of surgical patients. Einstein (Sao Paulo, Brazil), v. 14, n. 1, p. 18-24, 2016.

102 - BYRNES, A. et al. Use of hand grip strength in nutrition risk screening of older patients admitted to general surgical wards. Nutr Diet, v. 75 , n. 5 , p. 520526, 2018.

103 - SCHAG, C.C.; HEINRICH, R.L.; GANZ, P.A. Karnofsky Performance Status Revisited: Reliability, Validity, and Guidelines. Journal of Clinical Oncology, v.2, n.3, mar. 1984.

104 - SCHAAFSMA, J.; OSOBA, D. The Karnofsky performance status scale reexamined: a cross-validation with de EORTC-C30. Quality of life Research, n.3, p. 413-24, 1994.

105 - PUIGGRÒS, C. e colab. Elíndice de Karnofsky como predictor de mortalidad en pacientes con nutrición enteral domiciliaria. Nutricion Hospitalaria, v. 24, n. 2, p. 156-160, 2009.

106 - MODESTO, A. P. et al. Impact of the Karnofsky performance status on survival and its dynamics during the terminal year of peritoneal dialysis patients. Peritoneal Dial Int., v.38, n. 1, p. 24-29, 2018.

107 - GUL, B. et al. The relationship between nutritional status and prognosis in patients with locally advanced and advanced stage lung cancer. Supportive Care in Cancer, 2020. 
108 - MALTONI, M., \& AMADORI, D. Prognosis in advanced cancer. Hematology/Oncology Clinics of North America, v.16, n.3, p.715-729, 2002.

109 - CASTILLO-MARTÍNEZ L. et al. Nutritional Assessment Tools for the Identification of Malnutrition and Nutritional Risk Associated with Cancer Treatment. Revista de investigación clínica. v.70, n.3, p.121-125, 2018.

110 - REBER, E. et al. Nutritional Risk Screening and Assessment. Journal of Clinical Medicine, v. 8, n. 7, p. 1065, 2019.

111 - CONTRERAS-BOLÍVAR, V. et al. Glim criteria using hand grip strength adequately predict six-month mortality in cancer inpatients. Nutrients, v. 11, n. 9, p. 1-13, 2019.

112 - CASTILLO-MARTÍNEZ L. et al. Nutritional Assessment Tools for the Identification of Malnutrition and Nutritional Risk Associated with Cancer Treatment. Revista de investigación clínica. v.70, n.3, p.121-125, 2018. 


\section{ANEXO 1}

\begin{tabular}{|l|l|}
\hline \multicolumn{2}{|c|}{ Escala de performance de Karnofsky } \\
\hline $100 \%$ & Sem sinais ou queixas, sem evidência de doença \\
\hline $90 \%$ & Minimos sinais e sintomas, capaz de realizar suas atividades com esforço \\
\hline $80 \%$ & Sinais e sintomas maiores, realiza suas atividades com esforço \\
\hline $70 \%$ & Cuida de si mesmo, não é capaz de trabalhar \\
\hline $60 \%$ & Necessita de assistência ocasional, capaz de trabalhar \\
\hline $50 \%$ & Necessita de assistência considerável e cuidados médicos frequentes \\
\hline $40 \%$ & Necessita de cuidados médicos especiais \\
\hline $30 \%$ & $\begin{array}{l}\text { Extremamente incapacitado, necessita de hospitalização, mas sem iminência } \\
\text { de morte }\end{array}$ \\
\hline $20 \%$ & Muito doente, necessita de suporte \\
\hline $10 \%$ & Moribundo, morte iminente \\
\hline
\end{tabular}




\section{ANEXO 2}

TRIAGEM DE RISCO NUTRICIONAL - NRS 2002 - NUTRITIONAL RISK SCREENING

\begin{tabular}{|c|c|c|c|c|}
\hline \multicolumn{4}{|c|}{ Parte 1. Triagem inicial } & Näo \\
\hline \multicolumn{4}{|c|}{ Paciente apresenta IMC $<20,5 ?$} & \\
\hline \multicolumn{4}{|c|}{ Heuve perda de peso nos útimes 3 mescs? } & \\
\hline \multicolumn{4}{|c|}{ Houve redução na ingestâo de alimentos na ultima semana? } & \\
\hline \multicolumn{4}{|c|}{\begin{tabular}{|l|l} 
Paciente apresenta doença grave, esia em mau estajo geral ou em UII? & \\
\end{tabular}} & \\
\hline \multicolumn{5}{|c|}{$\begin{array}{l}\text { Sim: se a resposta for "sim" para qualquer uma das quesiōes, continue e preencha a parte } 2 \\
\text { Não: se a resposta for "náo" para todas as questöes, reavalie o paciente semanalmente. Se o paciente tver indização de } \\
\text { cirurgia de grande porte, deve-se considerar Terapia Nutricional para evitar riscos associados. Continue e preencha a parte } 2 .\end{array}$} \\
\hline \multicolumn{5}{|c|}{ Parte 2. Triagem do risco nutricional } \\
\hline \multicolumn{2}{|r|}{ Estado Nutricional } & \multicolumn{3}{|c|}{$\begin{array}{l}\text { Gravidade da Doença } \\
\text { (efeito do estresse metabólico no aumento das necessidades } \\
\text { nutricionais) }\end{array}$} \\
\hline $\begin{array}{c}\text { Ausenie } \\
\text { (pontuaçēo 0) }\end{array}$ & Fstado nutricional normal & $\begin{array}{c}\text { Ausente } \\
\text { (pontuação 0] }\end{array}$ & \multicolumn{2}{|c|}{ Necessidades nutirinnais normais } \\
\hline $\begin{array}{l}\text { Leve } \\
\text { (pontuaçầo 1) }\end{array}$ & $\begin{array}{l}\text { Perda de peso }>5 \% \text { em } 3 \text { meses ou; } \\
\text { Ingestäo alimentar abaixo de } 50-75 \% \\
\text { da necessidade ncrmal da semana } \\
\text { anteror. }\end{array}$ & $\begin{array}{l}\text { Leve } \\
\text { (pontuaçẩo } 1 \text { ) }\end{array}$ & \multicolumn{2}{|c|}{$\begin{array}{l}\text { Fratura de quadril; Pacicntes crónicos com } \\
\text { complicą̧ōes agudas : cirrose, DPOC, dabetes, } \\
\text { Câncer, hemodiá ise crônica. }\end{array}$} \\
\hline $\begin{array}{c}\text { Moderajo } \\
\text { (pontuaçio 2) }\end{array}$ & $\begin{array}{l}\text { Perda de peso }>5 \% \text { em } 2 \text { meses ou; } \\
\text { IMC } 18,5-20,5+\text { condição geral } \\
\text { comprometido ou; Ingcstão alimontar } \\
\text { entre } 25-60 \% \text { da necessidade normal } \\
\text { da sermana antel ol. }\end{array}$ & $\begin{array}{l}\text { Moderajo } \\
\text { (pontuaçäo } 2 \text { ) }\end{array}$ & \multicolumn{2}{|c|}{$\begin{array}{l}\text { Crurga abdominal de grande porte; AVC; } \\
\text { Pncumonia gravc; Docnças malignas } \\
\text { hematologicas ileucemas e Infomas) }\end{array}$} \\
\hline $\begin{array}{c}\text { Grave } \\
\text { (pontuagèo 3) }\end{array}$ & $\begin{array}{c}\text { Perda de peso }>5 \% \text { em } 1 \text { mes (> }>15 \% \\
\text { em } 3 \text { meses) ou; IMC }<18,5+ \\
\text { condiçăo geral entre } 0.25 \% \text { da } \\
\text { necessidade nomal da semana } \\
\text { anteror. }\end{array}$ & $\begin{array}{c}\text { Grave } \\
\text { (pontuaçâo 3) }\end{array}$ & $\begin{array}{l}\text { Traume craniano; Transplante de } \\
\text { Pacientes cm cuidados intensivos }\end{array}$ & $\begin{array}{l}\text { la óssea } \\
\text { CHE }=10)\end{array}$ \\
\hline \multicolumn{5}{|c|}{ ESCORE TOTAL: pontuação (estado nutricional) + pontuação (gravidade da doença) $\rightarrow$} \\
\hline Escore total $\geq 3$ & \multicolumn{4}{|c|}{ U paciente esta em nisco nutncional e a terapia nutncional deve ser iniciada. } \\
\hline Escore tolal $<3$ & \multicolumn{4}{|c|}{$\begin{array}{l}\text { No momento, o pacierte näo apresenta risco nutricional, mas deve ser reavaliado semanaimente Se o } \\
\text { paciente tiver indicaçāo de cirurgia de grande porte, deve-se considerar terapia nutricional para evitar riscos } \\
\text { assnriadns }\end{array}$} \\
\hline
\end{tabular}

- PONTUAÇÃO $=1 \rightarrow$ a ncocss dade protcico cslá aumentada mos o Deficít Protcica pode scr recuperado pela alimentaçäo oral cu uso de suplementos, na maior parte dos casos.

- PONTUAÇÃO $=2 \rightarrow$ a necess dade proteica esia substancialmente aumentada, e o Deficit Froteico pode ser recupcrado no maior parte dos casos com o uso de suplemontos orais/d ota cnteral.

- PONTUAC̣ĀO $=3 \rightarrow$ a necess dade proteica esiá substancialmerte aumentada e não pode ser recuperada somente pelo uso de suplementos oraisidieta enteral 


\section{ANEXO 3}

Critério GLIM Para Diagnóstico de Desnutrição - Adaptado de T. Cederholm et al. / Clinical Nutrition xxx (2018)

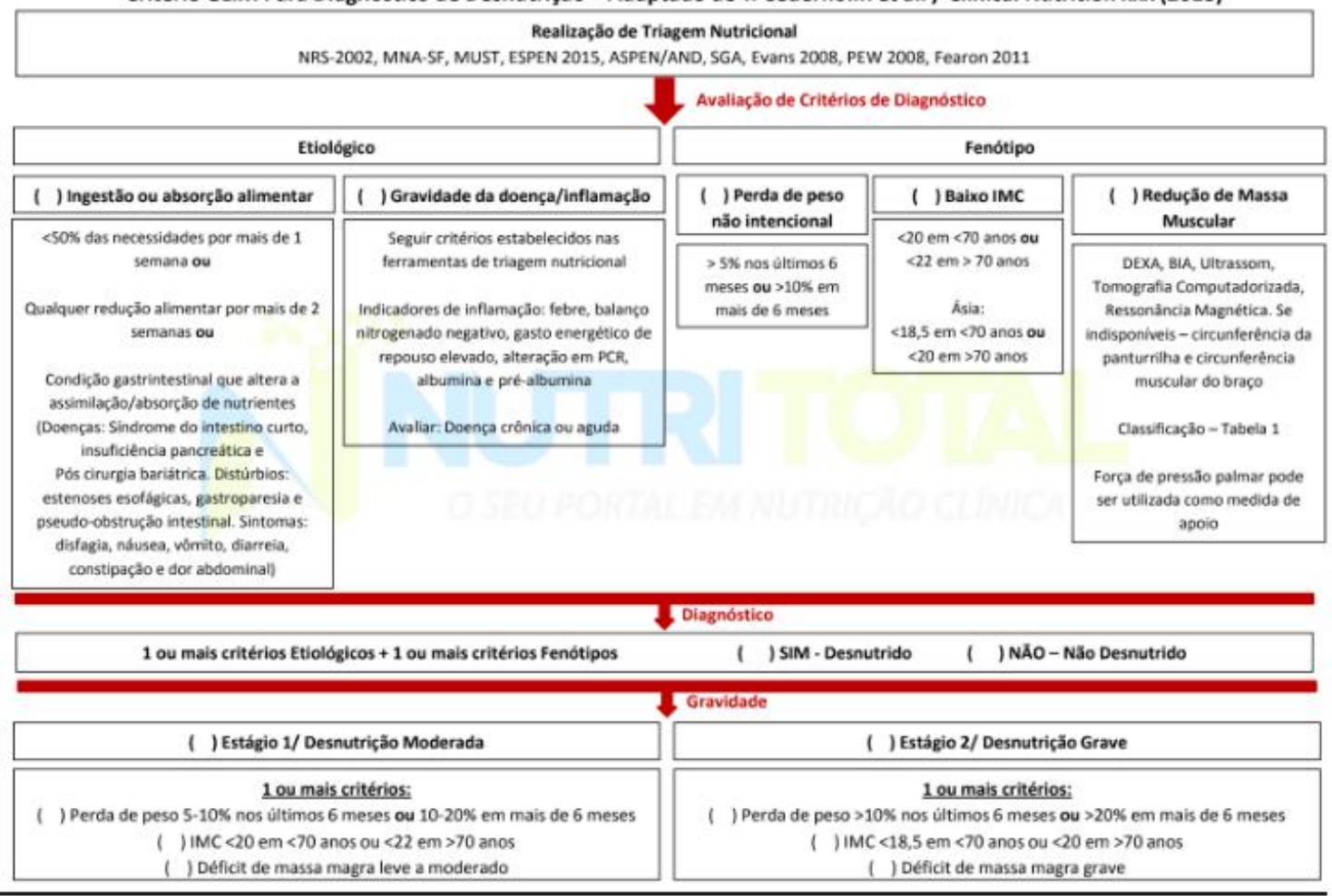

Avaliação da Redução da Massa Muscular - Adaptado de T. Cederholm et al. / Clinical Nutrition xxx (2018)

\begin{tabular}{|c|c|c|}
\hline Parâmetro & Ponto de corte-Homens & Ponto de corte - Mulheres \\
\hline $\begin{array}{c}\text { Índice de Massa muscular apendicular }\left(\mathrm{Kg} / \mathrm{m}^{2}\right) \\
\text { Cruz-Jentoft AJ et al, } 2010\end{array}$ & $<7.26$ & $<5.25$ \\
\hline $\begin{array}{l}\text { Índice de Massa muscular apendicular }\left(\mathrm{Kg} / \mathrm{m}^{2}\right) \\
\text { Alfonso Cruz-Jentoft, Personal communication for } \\
\text { EWGSOP2 (a ser publicado) }\end{array}$ & $<7$ & $<6$ \\
\hline $\begin{array}{l}\text { Índice de Massa muscular apendicular - DEXA }\left(\mathrm{Kg} / \mathrm{m}^{2}\right) \\
\text { Chen LK et al, } 2016\end{array}$ & $<7$ & $<5.4$ \\
\hline $\begin{array}{l}\text { Índice de Massa muscular apendicular - BIA }\left(\mathrm{Kg} / \mathrm{m}^{2}\right) \\
\text { Chen LK et al, } 2016\end{array}$ & $<7$ & $<5.7$ \\
\hline $\begin{array}{l}\text { Indice de Massa Livre de Gordura }\left(\mathrm{Kg} / \mathrm{m}^{2}\right) \\
\text { Cederholm T et al, } 2015\end{array}$ & $<17$ & $<15$ \\
\hline $\begin{array}{c}\text { Massa Muscular Apendicular (Kg) } \\
\text { Baumgartner RN et al, } 1998\end{array}$ & $<21.4$ & $<14.1$ \\
\hline $\begin{array}{l}\text { Massa Muscular Apendicular (MMA) ajustada pelo } \\
\qquad \text { IMC (MMA/IMC) } \\
\text { Chiles Shaffer N et al, } 2017\end{array}$ & $<0.725$ & $<0.591$ \\
\hline
\end{tabular}

